Amasya Ilahiyat Dergisi - Amasya Theology Journal

ISSN 2667-7326 | e-ISSN 2667-6710

Haziran / June 2021, 16: 229-266

\title{
Din Kültürü ve Ahlak Bilgisi Aday Öğretmenleri ve Danışman Öğretmenlerinin Gözüyle Aday Öğretmen Yetiştirme Eğitimi ve Süreci*
}

\author{
Ahmet YEMENICI \\ Dr. Öğr. Üyesi, Ankara Yıldırım Beyazıt Üniversitesi, İslami İlimler Fakültesi, \\ Din Bilimleri Anabilim Dalı \\ Assistant Professor, Ankara Yıldırım Beyazıt University, \\ Faculty of Islamic Studies, Departman of Philosophy and \\ Studies of Religion \\ Ankara, Turkey \\ ayemenici@yahoo.com \\ orcid.org/0000-0002-7549-5074
}

Makale Bilgisi / Article Information

Makale Türü / Article Types: Araştırma Makalesi / Research Article

Geliş Tarihi / Received: 27 Şubat / February 2021

Kabul Tarihi / Accepted: 5 Mayıs / May 2021

Yayın Tarihi / Published: 30 Haziran / June 2021

Yayın Sezonu / Pub. Date Season: Haziran / June

Sayı / Issue: 16 Sayfa / Pages: 229-266

Atıf / Cite as: Yemenici, Ahmet. "Din Kültürü ve Ahlak Bilgisi Aday Öğretmenleri ve Danışman Öğretmenlerinin Gözüyle Aday Öğretmen Yetiştirme Eğitimi ve Süreci [Teacher Candidate Training and Training Process from the Perspective of Religious Culture and Moral Knowledge Teacher Candidates and Adviser Teachers]". Amasya Ilahiyat Dergisi-Amasya Theology Journal 16 (June 2021): 229-266.

https://doi.org/10.18498/amailad. 887766.

İntihal / Plagiarism: Bu makale, en az iki hakem tarafından incelendi ve intihal içermediği teyit edildi. / This article has been reviewed by at least two referees and scanned via a plagiarism software.

\footnotetext{
* Araştırma, Ankara Yıldırım Beyazıt Üniversitesi Etik Kurulunun 02.08.2016 Tarihli ve 354 Sayılı onayı alınarak yürütülmüştür.
} 
230 | A. YEMENICİ / Din Kültürü ve Ahlak Bilgisi Aday Öğretmenleri ve Danışman Öğretmenlerinin Gözüyle Aday Öğretmen Yetiştirme Eğitimi ve Süreci

Copyright $\odot$ Published by Amasya Üniversitesi, İlahiyat Fakültesi / Amasya University, Faculty of Theology, Amasya, 05100 Turkey. All rights reserved. https://dergipark.org.tr/amailad.

\section{Teacher Candidate Training and Training Process from the Perspective of Religious Culture and Moral Knowledge Teacher Candidates and Adviser Teachers}

\section{Abstract}

The Ministry of National Education has started a different application in the Teacher Candidate Training System in 2015-2016 academic year. In the application, teacher candidates were not sent to the schools they are appointed to; it was anticipated that they are trained under the supervision of adviser teachers and at the schools where those adviser teachers work for a semester. This first application regarding the teacher candidate training system contains various aspects for candidate training. However, there are limited number of studies on this application which is tried for the first time. In this article on that new application, it is aimed to establish what teacher candidate training process means and the functionality in the teacher candidate training studies from the perspective of candidate and adviser Religious Culture and Moral Knowledge teachers. Taking the searches on teacher candidate training models into consideration, the data on this different application which is tried for the first time would provide significant feedback regarding teacher training. Furthermore, it would also enable us to understand religious education teacher training processes from the perspective of candidates and advisers. In this respect, the fundamental question of the research is expressed as "What do teacher candidate training and training process mean from the perspective of candidate and adviser Religious Culture and Moral Knowledge teachers?

The study was carried out based on phenomenology approach which is one of the qualitative research methods. Research data was obtained by means of a semi-structured interview with 10 advisers and 8 teacher candidates who participated in the practice. Interview texts were analyzed by the researcher within the framework of phenomenological encoding.

In the results obtained from analyses, 5 main dimensions were found regarding the meaning of teacher candidate training. These are; 1. Being a teacher, 2. Rediscovering Learning and Teaching: Candidateship and Advising, 3. Teacher 
A. YEMENICI / Teacher Candidate Training and Training Process from the Perspective of Religious Culture and Moral Knowledge Teacher Candidates and Adviser Teachers | 231 Candidate Adviser Teacher Practice - Operation, 4. How and When a Teacher Can Be Happy?, 5. Area - Field Relation and Formation Training.

Some of the conclusions reached from the results obtained and discussions made within the framework of literature are as follows:

Teacher candidate training, which is tried for once unlike other practices, has had a supporting and teaching function both for candidates when they are starting the profession and for advisers in terms of their professional development and created an interactive environment between candidates and advisers.

In the processes of deciding the profession and in professional development, it was seen that the meaning ascribed to being a teacher and personality traits of strong role model teachers contain decisive elements.

This new practice regarding teacher candidate training and training enabled candidates to be more prepared against the course load which may be considered intense by means of not assigning courses to them in the critical stage of the profession. Considering that teaching profession takes place as more isolated in classroom practice than other colleagues, it was found out that such practices contribute to eliminate many professional difficulties for beginners such as trial and error or quitting the job in the candidateship process.

Filling in forms, reporting and doing stationary works excessively beyond needs do not have a meaning beyond being a workload which does not contribute in the essence of the practice and affects other processes negatively.

In relation to personal rights, the fact that the wage paid to practice teachers for trainee students is not paid to the advisers in teacher candidate process is considered as a contradictory situation.

As an opportunity provided by the practice, feedback that candidates and advisers give to each other, reactions and attention that they get from teachers, parents and the environment made them happy as a teacher.

When the theoretical and practical foundations of the relationship between needs and demands of the field cannot be set with theology field courses, perception of inadequacy occurs in the further stages of professional development starting from teacher candidate period in terms of both field courses and formation courses.

Keywords: Religious Education, Teacher Candidate, Teacher Candidate Training, Adviser Teacher, Religious Culture and Ethic Teachers. 
232 | A. YEMENICİ / Din Kültürü ve Ahlak Bilgisi Aday Öğretmenleri ve Danışman Öğretmenlerinin Gözüyle Aday Öğretmen Yetiştirme Eğitimi ve Süreci

\section{Din Kültürü ve Ahlak Bilgisi Aday Öğretmenleri ve Danışman Öz Öğretmenlerinin Gözüyle Aday Öğretmen Yetiştirme Eğitimi ve Süreci}

Milli Eğitim Bakanlığı Aday Öğretmen Yetiştirme Sisteminde 2015-2016 eğitimöğretim yılında farklı bir uygulamaya gitmiştir. Uygulamada aday öğretmenler atandıkları okullara gönderilmemiş, bir dönem danışman öğretmenlerinin gözetiminde ve bu danışmaların görev yaptıkları okulda yetiştirilmeleri öngörülmüştür. Aday öğretmen yetiştirme sistemine yönelik bu ilk uygulama, mesleğin en kritik aşması olan adaylık eğitimi için farklı yönler taşımaktadır. Buna karşın bir defa denenmiş olan uygulama üzerinde az sayıda araştırma bulunmaktadır. Söz konusu uygulamayı konu alan bu makalede, aday ve danışman DKAB öğretmenleri gözünden aday öğretmen yetiştirme sürecinin ne anlama geldiği ve öğretmen yetiştirme çalışmalarındaki işlevselliğinin tespit edilmesi amaçlanmaktadır. Aday öğretmen yetiştirme modelleri üzerindeki arayışlar dikkate alındığında bir kez denenen bu farklı uygulama ile ilgili veriler, öğretmen eğitimine ilişkin önemli dönütlerin ortaya çıkmasını sağlayacaktır. Ayrıca adaylık eğitimi çerçevesinde, din eğitimi öğretmen yetiştirme süreçlerini hem adayların hem de danışmanların gözünden anlama fırsatı sunacaktır. Bu bağlamda araştırmanın temel sorusu; "Aday ve danışman din kültürü ve ahlak bilgisi öğretmenlerinin gözünden aday öğretmen yetiştirme eğitimi ve süreci ne anlama gelmektedir?" şeklinde ifade edilmiştir.

Çalışma nitel araştırma yöntemlerinden görüngübilim (fenomenoloji) yaklaşımı esas alınarak yürütülmüştür. Araştırma verileri, uygulamaya katılan 10 danışman ve 8 aday öğretmen ile yapılan yarı yapılandırılmış görüşme ile elde edilmiştir. Görüşme metinleri, araştırmacı tarafından görüngübilimsel (fenomenolojik) kodlama çerçevesinde çözümlenmiştir.

Çözümlemelerden elde edilen bulgularda, aday öğretmen eğitiminin anlamına ilişkin 5 temel boyuta ulaşılmıştır. Bunlar; 1. Öğretmen olmak, 2. Öğrenmenin ve Öğretmenin Yeniden Keşfi: Adaylık ve Danışmanlık, 3. Aday Öğretmen Danışman Öğretmen Uygulaması - İşleyişi, 4. Bir Öğretmen Nasıl ve Ne zaman Mutlu Olabilir? 5. Alan - Saha İlişkisi ve Formasyon Eğitimi şeklinde ifade edilmiştir.

Elde edilen bulgulardan ve alanyazın çerçevesinde yapılan tartı̧malardan ulaşılan sonuçlardan bazıları şöyledir.

Diğer uygulamalardan farklı olarak bir kez denenmiş olan aday öğretmen eğitimi, hem adaylara yönelik mesleğe başlarken hem de danışmanlar için 
A. YEMENICI / Teacher Candidate Training and Training Process from the Perspective of Religious Culture and Moral Knowledge Teacher Candidates and Adviser Teachers | 233 mesleki gelişimleri açısından destekleyici ve öğretici bir işlev görmüş, adaylar ve danışmanlar arasında etkileşim ortamı oluşturmuştur.

Mesleğe karar verme süreçlerinde ve mesleki gelişimde, öğretmen olmaya yüklenen anlamın ve güçlü rol model öğretmenlerin kişilik özelliklerinin belirleyici ögeler taşıdığı görülmüştür.

Aday öğretmen yetiştirme eğitimi ve sürecine ilişkin bu yeni uygulama, mesleğin kritik aşamasında adayları doğrudan derse sokmayarak yoğun gelebilecek ders yükü karşısında onların daha hazırlıklı olmalarını sağlamıştır. Öğretmenlik mesleğinin sınıf pratiğinde diğer meslektaşlardan izole bir şekilde gerçekleştiği dikkate alındığında, yeni başlayanlar için bu tür uygulamaların adaylık sürecindeki deneme yanılma ya da görevi bırakma gibi pek çok mesleki zorluğu gidermeye katkı sunduğu ortaya çıkmıştır.

İhtiyaçların ötesinde aşırı derecede form doldurma, raporlama ve kırtasiye işlemeleri uygulamanın özüne katkı yapmayan, diğer süreçleri de olumsuz etkileyen bir iş yükü olmanın ötesinde bir anlam taşımamıştır.

Özlük hakları ile ilgili olarak stajyerlikte uygulama öğrencileri için uygulama öğretmenlerine ödenen ücretin, aday öğretmen eğitimi sürecinde danışmanlar için verilmemesi çelişkili bir durum olarak görülmüştür.

Uygulamanın getirdiği bir fırsat olarak, adayların ve danışmanların birbirlerine verdikleri dönütler, öğrencilerden, velilerden ve çevreden aldıkları tepkiler ve gördükleri ilgi, bir öğretmen olarak mutlu olmalarını sağlamıştır.

İlahiyat alan dersleri ile sahanın ihtiyaç ve talepleri arasındaki ilişkinin teorik ve pratik temelleri kurulamadığında hem alan dersleri hem de formasyon dersleri açısından, aday öğretmenlik döneminden başlamak üzere mesleki gelişimin ilerleyen aşamalarında yetersizlik algısı ortaya çıkmaktadır.

Anahtar Kelimeler: Din Eğitimi, Aday Öğretmen, Aday Öğretmen Eğitimi, Danışman Öğretmen, Din Kültürü ve Ahlak Bilgisi Öğretmenleri.

\section{Giriş}

Öğretmen eğitimi hangi bileşenlerden oluşmaktadır sorusu önemini ve güncelliğini sürekli korumaktadır. Eğitimin paydaşları ve bileşenleri üzerinde görünen her türlü değişiklik, öğretmen eğitimi anlayışına ve öğretmen olmanın anlamına yansımaktadır. 
234 I A. YEMENICİ / Din Kültürü ve Ahlak Bilgisi Aday Öğretmenleri ve Danışman Öğretmenlerinin Gözüyle Aday Öğretmen Yetiştirme Eğitimi ve Süreci

Eğitim alanındaki gelişmelerle öğretmenlik mesleği alanındaki dönüşümlerin eş zamanlı olduğu, birbirlerini tetikledikleri, bu ilişkinin ve bağlantının kurulamadığı durumlarda teorik ve pratik boyutlarıla aksaklıkların ortaya çıtı̆̆ tecrübe edilmiştir (Akyüz, 2012, 81; Akyüz, 1991, 222; Öztürk, 1996, 2; Binbaşığlu, 1995, 453).

Ülkemiz eğitim tarihinde, hayatın pek çok alanında yaşanan değişimin eğitim alanını da tüm bileşenleriyle etkilemiş olduğunu, Tanzimat sonrası tartışmalarda ve arayışlarda görmek mümkündür (Zengin, 2004, 11 - 29; Akyüz, 2012, 81). Uzun süreli arayışlar ve gelişmeler neticesinde kuruluşunun ilk yıllarından itibaren ülkemizde de öğretmen yetiştirme politikalarında önemli aşamalar kaydedilmiştir (Öztürk, 1996, 252; Akyüz, 2012, 359).

Geçmiş tecrübeler dikkate alındığında, öğretmenlerin hizmet öncesi eğitimlerinden göreve başlama ve hizmet içinde geçirdikleri yıllarda karşılaştıkları deneyimler göz ardı edilerek eğitimin diğer bileşenlerinden beklenen ve arzu edilen neticeyi almak ne ölçüde mümkün olacaktır? sorusu daha da anlamlı hale gelmektedir. Zira okulun imkân ve sınırları içinde, öğretmenlerin akran ve aile kadar eğitim kazanımlarında öğrenciler üzerinde etkili olduğu (Hurn, 2018, 180) yönündeki veriler dikkate almaya değer boyuttadır.

Özellikle eğitim alanında başarılı olan ülkelerin, öğretmenlerine ve onların eğitimlerine her açıdan öncelik verdikleri, söz konusu ülkelerde eğitime dair pek çok çıktı ile daha da görünür hale gelmiştir (Gültekin, 2018, 404).

Hizmet öncesi eğitim, öğretmenliğe başlama ve hizmet içindeki görev bir bütün olarak ele alındığında, öğretmen eğitiminde önemli ve kritik aşamalardan birini hiç şüphesiz adaylık süreci oluşturmaktadır.

Pek çok OECD ülkesinde istifa eden ya da görevden alınan 3 öğretmenden bir tanesinin mesleğin ilk 3 - 5 yıllarında olması dikkat çekmekte ve öğretmenlerin bu kritik dönemde desteklenmesi gereği üzerinde durulmaktadır (İlyas vd., 2016,15).

Hassas bir dönem olması nedeniyle göreve başlama ve adaylık eğitimi, ülkelerin öğretmen eğitimi politikalarında belirleyici temalardan biri olarak kabul edilmektedir. Ülkemizde de Öğretmen Strateji Belgesinde (Öğretmen Strateji Belgesi/ÖSB, 9 Haziran 2017) adaylık ve uyum eğitimi ana bileşenlerden birini oluşturmaktadır. 
A. YEMENICI / Teacher Candidate Training and Training Process from the Perspective of Religious Culture and Moral Knowledge Teacher Candidates and Adviser Teachers | 235

Aday öğretmenlere yönelik eğitim süreçlerini, gerekli iş ve işlemleri düzenleyen mevzuatta aday öğretmen kavramı, "öğretmenlikte adaylığ daha önce kaldırılmamış olanlardan öğretmenliğe ilk atama kapsamında atananları" ifade eder şeklinde tanımlanmıştır (Aday Öğretmen Yetiştirme Sürecine İlişkin Yönerge/AÖYSIY, 2016, md. 4/1/a).

Göreve başlamada adaylık eğitimini önemli ve gerekli kılan nedenlerden bir diğerini, hizmet öncesinde mesleki anlamda adayların ihtiyaç duydukları eğitimleri alma konusunda yaşanan sorunlar oluşturmaktadır (Seferoğlu, 2004, 42; Gökyer, 2012, 126). Diğer yandan ihtiyaç duyulan öğretmenlik yeterliklerinin hizmet öncesinde tamamen kazanılması, lisans eğitiminin imkân ve sınırları içinde ne ölçüde gerçekleşebilir sorusu, tartışma eksenlerinden bir diğeridir.

Göreve başlatma programları açısından bakıldığında, atandıkları anda doğrudan derse girerek göreve başlama uygulamasında adayların bir takım sıkıntı yaşadıkları ve danışmanlarından daha kapsamlı destek alma ihtiyacı duydukları belirtilmekte, bu verilerden hareketle iyi tasarlanmış mentörlük (danışmanlık) sisteminin verimli olacağı yönünde öneriler üzerinde durulmaktadır (Balkar - Şahin, 2014, 90; a.mlf., 2015; Gökçe, 2013, 154).

Göreve başlama ve adaylık eğitimi alanında yürütülen süreçlere daha yakından bakıldığında, farklı ülkelerde olduğu üzere ülkemizde de adaylık eğitimine yönelik zaman içinde değişik uygulamalar söz konusu olmuştur (Kozikoğlu - Senemoğlu, 2018, 343).

Milli Eğitim Bakanlığınca göreve başlama ve adaylık eğitimi için farklı ve yeni uygulamalardan biri, Şubat 2016 tarihinde atanan aday öğretmenlere yönelik yapılan düzenleme ile (MEB Aday Öğretmen Yetiştirme Sürecinin Ayrıntıları Belli Oldu/AÖYS, 18 Şubat 2016) 2016 yılı Mart ayında yürürlüğe konmuştur (Aday Öğretmen Yetiştirme Sürecine İlişkin Yönerge/AÖYSIY, Mart 2016). Bu uygulamaya göre aday öğretmenler bir yıllık adaylık süreçlerinin ilk altı ayında yetiştirme programı kapsamında danışmanlarının okulunda eğitime tabi tutulacaklardır. Aday öğretmenlere yetiştirme sürecinde bağımsız olarak derse girme ve nöbet görevi verilmemiş, aday öğretmenler bu süreçte derslere danışman öğretmen nezaretinde girmişlerdir. Uygulama bu anlamda öncesine kıyasla bir yenilik getirmiştir. Aday öğretmenlerin 
236 | A. YEMENICİ / Din Kültürü ve Ahlak Bilgisi Aday Öğretmenleri ve Danışman Öğretmenlerinin Gözüyle Aday Öğretmen Yetiştirme Eğitimi ve Süreci

birinci performans değerlendirmesi ise Millî Eğitim Bakanlığı Öğretmen Atama ve Yer Değiştirme Yönetmeliği çerçevesinde yapılmıştır (Milli Eğitim Bakanlığı Öğretmen Atama ve Yer Değiştirme Yönetmeliği/MEBÖAYDY, 17 Nisan 2015).

Aday öğretmen eğitimi sürecinde görev alacak başta danışman öğretmenler olmak üzere diğer görevlilerin nitelikleri ve yapacakları iş ve işlemler, ilgili yönerge (AÖYSİY, Mart 2016) çerçevesinde belirlenmiştir. $\mathrm{Bu}$ kapsamda danışman öğretmenlere, aday öğretmen yetiştirme programıla ilgili eğitim verilmiştir (MEB, 18 Şubat 2016).

Gelinen süreçte ortaya çıan ihtiyaçlar gerekçesiyle yeni uygulamadan vazgeçilmiş, 12.10.2016 tarihli ve 43501582-774-E11237687 sayılı makam oluru ile (Milli Eğitim Bakanlı̆̆1 Aday Öğretmen Yetiştirme Programı Konulu Valiliklere Gönderilen Bakanlık Yazısı/ MEBAÖYP, 17 Ekim 2016, İlgi d.) Ekim 2016 tarihinden itibaren eski uygulamalara dönülmüştür.

Bir dönemle sınırlı kalmış olması, ilk kez uygulanması ve belirgin özellikleri dikkate alındığında söz konusu aday öğretmen uygulamasına yönelik veriler daha da ayrı bir önem taşımaktadır.

Yapılan araştırmalara bakıldığında, uygulamaya ilişkin az sayıda çalışma yapıldığı görülmektedir (İlyas vd., 2016; Sarıkaya vd., 2017; Topsakal - Duysak, 2017; Kozikoğlu - Soyalp, 2018; Özan - Nanto, 2018; Algur, 2019). Özellikle ilahiyat temel alanına dayalı olarak atanan öğretmenlere ilişkin DKAB aday öğretmenler ve danışman öğretmenler üzerinde yeterli düzeyde çalışma yapılmadığı anlaşılmaktadır.

Öğretmen eğitimi ve din eğitimine yönelik arayışlar göz önünde bulundurulduğunda, hizmet öncesi, göreve başlama ve adaylık süreci ile hizmet içindeki gelişim birlikte düşünülerek öğretmen eğitiminin bir bütünlük içinde ele alınması, günümüzdeki yaklaşımlar bakımından gerekli görülmektedir (Aydın, 2017, 383). DKAB öğretmen yeterlikleri üzerinde yürütülen çalışmalar (Doğan - Altaş, 2002, 109; Işıkdoğan, 2011, 553; Koç, 2011, 523) dikkate alındığında, aday öğretmenlikten danışman öğretmenliğe bir bütünlük içinde bu özelliklerin uygulamada bir kazanıma dönüşmesi halinde amaçlanan sonuçlara ulaşılabileceğine vurgu yapilmaktadir (Ev, 2015, 90).

Hem aday öğretmenlerin göreve başlama süreçlerini hem de görevde olan danışman öğretmenlerin hizmet içinde uygulamaya yönelik 
A. YEMENICI / Teacher Candidate Training and Training Process from the Perspective of Religious Culture and Moral Knowledge Teacher Candidates and Adviser Teachers | 237 deneyimlerini birlikte görme fırsatı vermesi bakımından bu ilk uygulama, din eğitimi alanında da öğretmen eğitimine yönelik sahayı görme şansı sunmaktadır.

DKAB öğretmenlerinin eğitimine yönelik süreç içinde ortaya çıan birikim, yaşanan sorunlar, arayışlar ve tartışma konuları dikkate alındığında; aday - danışman din kültürü ve ahlak bilgisi öğretmenlerinin aday öğretmen uygulamasına ilişkin deneyimleri önem arz etmektedir.

$\mathrm{Bu}$ bağlamda araştırmanın amacı, aday öğretmen yetiştirme uygulamasını adayların ve danışmanların deneyimlerinden hareketle anlayarak öğretmen eğitimi çalışmalarındaki işlevselliğinin tespit edilmesine katkı sunmaktır.

Araştırmanın temel sorusu; Aday ve danışman din kültürü ve ahlak bilgisi öğretmenlerinin gözünden aday öğretmen yetiştirme eğitimi ve süreci ne anlama gelmektedir? şeklinde ifade edilmiştir. Temel soru çerçevesinde şu alt sorulara cevap aranmıştır.

1. Adayların ve danışmanların öğretmen olma kararlarına yön veren deneyimler nelerdir?

2. Aday öğretmenlik ve danışman öğretmenlik uygulaması, mesleki gelişim bağlamında ne anlama gelmektedir?

3. Aday öğretmen yetiştirme eğitimi ile ilgili program, iş ve işlemler adaylara ve danışmanlara nasıl yansımıştır?

4. Bir öğretmeni mesleğinde başarılı ve mutlu eden deneyimler nelerdir?

5. Adayların ve danışmanların hizmet öncesi alan eğitimleri ve formasyon süreçleri aday öğretmen yetiştirme eğitimi ve uygulaması ile nasıl ilişkilendirilmiştir?

\section{Yöntem}

Araştırmanın yaklaşımı: Çalışma nitel araştırma yöntemlerinden görüngübilim (fenomenoloji) yaklaşımı esas alınarak yürütülmüştür (Mayring, 2011, 110; Patton, 2014, 104). Fenomenolojik araştırma yaklaşımı, deneyimlerin değişkenlik göstermeyen özünü ortaya çıararak fenomenle ilgili bireysel deneyimleri evrensel nitelikteki açılamaya indirgemeyi amaçlamaktadır (Creswell, 2013, 77). Bu bağlamda aday ve danışman DKAB öğretmenlerinin aday öğretmen yetiştirme eğitimi sürecindeki yaşantılarından hareketle gerçekleştirilen çalışmada, aday ve 
238 | A. YEMENICİ / Din Kültürü ve Ahlak Bilgisi Aday Öğretmenleri ve Danışman Öğretmenlerinin Gözüyle Aday Öğretmen Yetiştirme Eğitimi ve Süreci

danışman öğretmen olma deneyimlerinin onlardaki anlamına ulaşılmaya çalışılmıştır.

Çalışma Grubu: Araştırmada uygulamayı bire bir yaşayan adaylardan ve danışmanlardan hareket edilmiştir. Bu çerçevede çalışmada danışman ve aday öğretmenlerin belirlenmesi için amaçlı örnekleme türlerinden maksimum çeşitlilik kullanılmıştır (Creswell, 2016, 154,158. 298). Veri doyumu dikkate alınarak (Merrıam, 2013, 79) 8 aday ve 10 danışman kadın-erkek öğretmene yer verilmiştir. Çalışmada öğretmenlerin isimleri kodlanarak belirtilmiştir.

Tablo 1: Çalışma Grubunda Yer Alan Aday ve Danışman Öğretmenlere İlişkin Bilgiler

\begin{tabular}{|l|l|l|l|l|l|}
\hline \multicolumn{2}{|l|}{ Aday Öğretmenler } & \multicolumn{3}{|c|}{ Danışman Öğretmenler } \\
\hline Say1 No: & Verilen kod & Yaş & Say1 No: & Verilen kod & $\begin{array}{l}\text { Yaş/Mesleki } \\
\text { Deneyim }\end{array}$ \\
\hline 1 & EAÖ1 & 29 & 1 & KDÖ1 & $53 / 21$ \\
\hline 2 & EAÖ2 & 25 & 2 & KDÖ2 & $50 / 27$ \\
\hline 3 & EAÖ3 & 25 & 3 & KDÖ3 & $50 / 26$ \\
\hline 4 & KAÖ1 & 29 & 4 & KDÖ4 & $52 / 28$ \\
\hline 5 & KAÖ2 & 24 & 5 & KDÖ5 & $42 / 15$ \\
\hline 6 & KAÖ3 & 24 & 6 & KDÖ6 & $53 / 21$ \\
\hline 7 & KAÖ4 & 24 & 7 & EDÖ1 & $45 / 22$ \\
\hline 8 & KAÖ5 & 24 & 8 & EDÖ2 & $50 / 27$ \\
\hline & & & 9 & EDÖ3 & $51 / 24$ \\
\hline & & & 10 & EDÖ4 & $-/ 30$ \\
\hline
\end{tabular}

Verilerin Toplanması: Fenomenolojik çalışmaların temel veri toplama yöntemi derinlemesine yapılan görüşmelerdir (Creswell, 2016, 81). Aday öğretmen uygulamasına katılan aday ve danışman öğretmenlerin yeni süreci nasıl anlamlandırdıklarını ortaya koymak için görüşmeler yapılması planlanmıştır. Araştırmayı kabul eden aday ve danışman öğretmenlerle bireysel, yüz yüze ve yarı yapılandırılmış açık uçlu mülakatlar (Creswell, 2016, 160) yapılmasına karar verilmiştir. Bu amaçla veri toplama aracı olarak yarı yapılandırılmış görüşme formu geliştirilmiştir. Formun geliştirilmesinde, alanyazın taraması yapılarak bir soru havuzu elde edilmiş, soru havuzundan araştırmanın amacına uygun olan sorular seçilerek görüşme formu oluşturulmuştur. Görüşme 
A. YEMENICI / Teacher Candidate Training and Training Process from the Perspective of Religious

Culture and Moral Knowledge Teacher Candidates and Adviser Teachers | 239

formu uzman görüşlerine sunularak gerekli düzeltmeler sorulara yansıtılmışır. Soruların anlaşılırlığını belirlemek amacıyla pilot uygulamalar yapılmış, pilot uygulamalardan sonra görüşme formuna son biçimi verilmiştir.

Ankara Yıldırım Beyazıt Üniversitesi Etik Kurul'un 02.08.2016 Tarihli ve 354 Sayılı onayı ve Ankara İl Milli Eğitim Müdürlüğ̈̈’nün izniyle, görüşmeler 2016 Ağustos ve Eylül ayları arasında gerçekleştirilmiştir. Görüşmeleri makalenin yazarı (araştırmacı) ve Ankara Yıldırım Beyazıt Üniversitesi Sosyal Bilimler Enstitüsü doktora öğrencisi yürütmüştür. Görüşmelerden önce araştırmanın amacı ve süreci hakkında katılımcılar bilgilendirilmiştir. Yüz yüze gerçekleştirilen görüşmeler, aday ve danışman öğretmenlerin izniyle ses kayıt cihazı kullanılarak kaydedilmiştir. Her görüşme en az bir saat sürmüştür.

Verilerin Çözümlenmesi: Görüşme kayıtları araştırmacı tarafından ve hizmet alım yolu ile metne dökülmüştür. Görüşme metinleri, araştırmacı tarafından görüngübilimsel (fenomenolojik) kodlama çerçevesinde çözümlenmiştir. Çözümleme sürecinde ilk aşamada, metinler üzerinde ön kodlamalar (açık kodlama) yapılmıştır. İkinci aşamada, araştırma soruları kodlarla ilişkilendirilerek eksenler oluşturulmuştur. Üçüncü aşamada, eksenler bağlamında açıklayıcı temalar (Saldana, 2019, 199 - 200) belirlenmiştir. Dördüncü ve son aşamada ise yeni aday öğretmen yetiştirme sisteminin anlamını, aday ve danışman öğretmenlerin deneyimlerinde açıklayan "öz"e ulaşılmıştır. Bu çözümleme süreci deşifre edilen her bir görüşme metni için ayrı ayrı yapılmış, ortaya çıan örüntüler çerçevesinde temel boyutlara ulaşılmıştır. Çözümlenen veriler sonucunda oluşan temalar yorumlanarak araştırma bulguları elde edilmiştir. Bulgularda aday ve danışman öğretmenlerle yapılan görüşmelerden ilgili temayı betimleyen alıntılara doğrudan yer verilmiştir. Uygulamanın Ekim 2016 yılında kaldırılması nedeniyle, sürecin ne yönde gelişeceğini görmek için yayın sürecinde belirli bir süre beklenmiştir.

Araştırmacının rolü: Görüngübilim araştırma yönteminde bilgi kişilerarası üretildiğinden, deneyimin sahibi olan kişiyle deneyimi yorumlayan araştırmacı arasındaki ilişkinin nasıl kurulduğu önemlidir ve bu ilişkide araştırmacının duygu ve düşüncelerinin farkında olarak 
240 | A. YEMENICİ / Din Kültürü ve Ahlak Bilgisi Aday Öğretmenleri ve Danışman Öğretmenlerinin Gözüyle Aday Öğretmen Yetiştirme Eğitimi ve Süreci

önyargılarını paranteze alması beklenir (Creswell, 2016, 79). Bu bağlamda çalışmada yer alan araştırmacıların da aday ve danışman öğretmenlik deneyimi olduğu için aday ve danışman öğretmenlik sürecine ilişkin önyargıları olabileceğinden, araştırmacı bu önyargıları keşfetmek amacıyla çeşitli tartışmalar ve sorgulamalar yapmıştır. Araştırmacılar mümkün olduğunca kendi önyargılarının farkında olarak ve onları paranteze alarak alan çalışmasına katılmışlardır.

Geçerlik ve Güvenirlik Çalışmaları: Nitel çalışmalarda bir araştırma süreçte ve sonuçta açık, tutarlı ve başka araştırmacılar tarafından teyit edilebilir olması koşuluyla alanyazına kattığı bilgi ve karşılaşılan sorunlara getirdiği çözüm önerileri ile değerlendirilir (Creswell, 2016, 255 - 265). Bu nedenle araştırmac1, elde ettiği bulguların gerçekliğine (inanılabilirlik / iç geçerlik), benzer durumlar ve ortamlar sağlandığında sonuçların geçerliğine (aktarılabilirlik/dış geçerlik), elde edilen bulguların verilerle tutarlı olmasına (tutarlılık/iç güvenirlik) ve verilerin nesnel bir yaklaşımla toplandığına ve yine nesnel bir yaklaşımla sonuçların ortaya konduğuna (teyit edilebilirlik/dış güvenirlik) ilişkin araştırmadaki süreçleri açılaması gerekir (Merrıam, 2013, 199 - 228; Yıldırım - Şimşek, 2013, 298).

Araştırmada inanılabilirliği sağlamak için araştırmacı aday ve danışman öğretmenler ile sık sık bir araya gelerek yoğun bir etkileşim içinde olmuştur. Araştırmacı görüşme öncesinde katılımcları araştırma süreci hakkında ayrıntılı bir şekilde bilgilendirerek ve dilediklerinde araştırmadan ayrılma imkânları olduğunu onlara açık biçimde belirterek yalnızca gönüllü katılımcıların araştırmaya katkı yapmasını sağlamıştır.

Araştırmada aktarılabilirliği sağlamak yani elde edilen sonuçların uygulanabilirliği için araştırma sürecine ilişkin ayrıntılı betimlemeler yapılmıştır. Bu kapsamda; araştırmacının rolü, katılımcıların nasıl belirlendiği, veri toplama aracının geliştirilmesi, verilerin toplanması ve çözümlenmesi ayrıntılı olarak açılanmıştır.

Güvenilir veriler elde etmek ve tutarlılığ sağlamak için araştırmacı yaptığı kodlamaları eğitim ve din eğitimi alanındaki diğer meslektaşlarının denetimine sunmuştur. Her bir kodlamanın ilgili anlamı açıklayıp açıklamadığı konusunda görüş alınmıştır. Ayrıca elde edilen ham veri ve kodlar başka araştırmacıların incelemesine imkân verecek biçimde saklanmaktadır. 
A. YEMENICI / Teacher Candidate Training and Training Process from the Perspective of Religious Culture and Moral Knowledge Teacher Candidates and Adviser Teachers I 241

Onaylanabilirlik/teyitedilebilirlik için çalışmanın her bir aşaması (veri toplama araçları, çözümleme ve raporlama) şeffaf bir biçimde yazılmıştır.

\section{Bulgular ve Yorum}

Araştırmada aday ve danışman öğretmen deneyimlerinden elde edilen veriler sonucunda aday öğretmen eğitiminin anlamına ilişkin 5 temel boyuta ulaşılmıştır.

1. Ögretmen olmak,

2.Öğrenmenin ve Öğretmenin Yeniden Keşfi: Adaylık ve Danışmanlık,

3. Aday Öğretmen - Danışman Öğretmen Uygulaması - İşleyişi,

4. Bir Öğretmen Nasıl ve Ne zaman Mutlu Olabilir?

5. Alan - Saha İlişkisi ve Formasyon Eğitimi.

\section{1. Öğretmen Olmak}

Meslek seçimine yönelik öğretmen olma tercihinde bazı etkenlerin belirleyici olduğu dikkat çekmektedir. Öğretmen olma kararında bir model öğretmenin oluşturduğu etki, belirleyici görünmektedir. Bu etki olumlu olabildiği gibi olumsuz şekilde de tezahür edebilmektedir. Diğer yandan hayatta iz birakan öğretmenlerin unutulmayan özellikleri, öğretmen olma tercihini nelerin belirlediğini, bir öğretmende bulunması gereken nitelikleri görme fırsatı sunmaktadır.

“Orada bir tane [edebiyat] öğretmenim vardı, ... Onu örnek aldığım için bu öğretmenlik mesleğini sevmeye başladım..."(EAÖ3).

“...çok sevdiğim, örnek aldığım öğretmenim sosyal bilgiler öğretmeniydi. Kendisi çok disiplinli, anaç, işte işini, mesleğini seven ve sevdiğini, ilgilendiğini hissettiren birisiydi... Şu anda hani ben bir konuyu anlatırken, anlatacağım zaman şöyle geriye dönüp bakıyorum. Sevdiğim öğretmenler nasıl anlatıyorlardı? Konulara hangi yönden yaklaşıyorlardı diye" (KAÖ2).

“...imam hatip lisesinde bir meslek dersi hocamız bu mesleği bize sevdirdi. Efendimizin de [Hz. Muhammed] öğretmenlik yaptığını ve insan yetiştirdiğini bize özendirici bir şekilde anlattı̆̆ için ben de onun gibi olmak istedim..."(EAÖ1).

Öğretmen olma kararında, insanlara bir şeyler öğretme arzusu ve insanların bu eylem karşısında yaşadıkları değişim, hissettikleri mutluluk, verdikleri tepki, öğretmen olma tercihini belirlemektedir. 
242 | A. YEMENICI / Din Kültürü ve Ahlak Bilgisi Aday Öğretmenleri ve Danışman Öğretmenlerinin Gözüyle Aday Öğretmen Yetiştirme Eğitimi ve Süreci

"Yani seviyorum birilerine bir şeyler öğretmeyi, anlatmayı, bir konu hakkında bilgi vermeyi..."(KAÖ3).

“Öğrencileri gördüğümde, öğrencilerdeki sıkıntıyı düzelttiğimde aslında kendi parçamda düğümlenmiş bir yer varmış da onu çözmüşüm gibi geliyor"(KAÖ1).

“Öğretmenlik benim aslında hayat felsefemdi ..." (KDÖ1).

\section{2. Öğrenmenin ve Öğretmenin Yeniden Keşfi: Adaylık ve Danışmanlık}

Aday öğretmen eğitimi ve danışman öğretmen olma süreci, aday ve danışman arasında bir öğrenme - öğretme deneyiminin yaşanmasına yol açmıştır. Uygulama öncesinde danışman öğretmenler için kısa süreli de olsa verilen eğitimler, kendi bilgi, yaklaşım ve yöntemlerini gözden geçirmelerine fursat vermiştir.

"Benim kendimi gözden geçirmeme de faydası oldu. Aa şu şöyle miydi? Şöyle yapsam daha iyi olurmuş diye." (KDÖ4).

Uygulamada danışman öğretmen eğitimine ilişkin görülen memnuniyet durumu ve verimlilik, danışman öğretmen eğitimine yönelik düzenlenen farklı gruplarda, verilen eğitimin bileşenlerine göre değişiklikler göstermiştir.

“[Danışman öğretmenlik eğitimi, eğitmen] Bence yeterliydi onlar. Süresi biraz daha uzun tutulabilirdi. Birde, dönem sonunda hani nasıl değerlendirdiniz? Ne buldunuz? ...[Süreç içinde] Çok kararsız kaldığım şeyler oldu "(KDÖ4).

“Daha somut anlaşılır bilgiler verebilirlerdi. Materyaller yeterli değildi. Kendi çabalarımla buldum...Ben koordinatörlerden yardım aldım tam diyemem"(EDÖ2).

Uygulama hem adayların hem de danışmanların bu süreçte mesleki anlamda ihtiyaçlarını ve önceliklerini keşfetmelerine yardımcı olmuştur.

“Öğrencilerin genel bilgi seviyesini öğrenmeye çok ihtiyacımız var. İş hayatına, eğer daha önce çalışmamışsa iş ortamı, iş hayatı nasıl olması gerekiyor? Ona ihtiyaç var. Yönetmelik, tüzük, kanun bilgisine gerçekten çok ihtiyaç var. Bir de o bölgenin yaşantısı, genel kültürü, genel bilgi seviyesi, adetleri, gelenekleri, hani veli profili nasıl?..." (KAÖ5).

“En fazla yeniliklerle ilgili, materyal geliştirme, işte EBA'ya benzeyen yabancıların hazırladığı Edmondo gibi, Sokrat TV gibi çok daha erken öğrenmek gerektiğini, yeni neslin okuduğu kitapları da takip etmek gerektiğini, çünkü biz yaş kuşağı olarak biraz onlara göre yaşlı kaldık. Gerçekten gayret ediyorum. Seminerlere katılıyorum. Hizmet içine gidiyorum, drama kursuna gitmeyi çok istedim,..hiç bana çıkmadı."(KDÖ3).

Danışman öğretmenler, adaylar tarafından izlendikleri ilk derslerde gerginlik hissettiklerini ifade etmişlerdir. Sınıfta olumsuz 
A. YEMENICI / Teacher Candidate Training and Training Process from the Perspective of Religious Culture and Moral Knowledge Teacher Candidates and Adviser Teachers | 243 öğrenci davranışları karşısında ne yapacakları ve nasıl çözümler üretebilecekleri konusunda kaygılanmışlardır. Öğrenme ortamlarının doğasında olan böylesi anlar ve danışmanların çözüm yaklaşımları öğretici olmuştur.

“ilk bir iki ders çok heyecanlandığımı hatırlıyorum. Çünkü ben nasıl onu gözlemlerken o heyecanlanacak, ben de aynı heyecanlandım. Fakat dersten çıktığında; -Hocam, iyi ki böyle bir şey de [sınıfta öğrenci ile hoş olmayan bir gerginlik] yaşadık dedi, çünkü hep olumlu güzel şeyler olmuyor ki. Onun için çok mutlu oldum dedi. Ama yine sabırla çözdünüz dedi. Bu bana şaşırtıcı geldi. En çok etkilendiğim şey bu oldu dedi.- Ve ben ayaklarım yerden kesildi mutluluktan (KDÖ3)."

Paylaşımcı ve iyimser okul iklimi başta adaylar olmak üzere öğretmenler arasında iyi bir iletişim ortamı oluşturmaktadır. Okul ikliminin oluşmasında idarecilerin de önemli bir etkiye sahip olduğu görülmektedir.

"Ben hep korkuyordum, böyle titreye titreye geldim. Hepsini çok seviyorum şu anda ve bana deseler ki bu okuldan gitme, tamam derim direkt yani. İdarecilerimiz olsun işte müdürümüz zaten melek gibi, diğer öğretmenlerimiz olsun yani hepsi gerçekten çok iyiler, çok yardımcı oldular" (EAÖ3).

İletişim açısından öğretmenler odası etkin ortamlardan biridir. Farklı bakış açılarına, iletişim biçimlerine ve dünya görüşlerine sahip öğretmenlerin sergiledikleri tavırlar, bir aday öğretmen için motive edici olduğu kadar bazen kötümserlik ve umutsuzluk da verebilmektedir. Bu durumda danışman öğretmen eşliğinde öğretmenler odasını solumak, bir aday için başlangıçta olumlu bir süreç anlamına gelmektedir.

“Öğretmenler odası hepimizin her halde problemli noktası oldu. İlk defa sonuçta girdik öğretmenler odasına, gençsin ilk defa farklı görüşlerle, farklı öğretmenlerle karşılaşıyorsun. Fevri çıkışlarımız olabilirdi. Ama olmadı, aksi şekilde danışman öğretmenler çok memnundu adaylarından." (KAÖ2).

\section{İşleyişi}

2.3. Aday Öğretmen Danışman Öğretmen Uygulaması ve

Aday öğretmen eğitimiyle ilgili iş ve işlemlerin adaylar ve danışmanlar tarafından nasıl deneyimlediği ve uygulamaya yansıması bakımından ne anlama geldiği boyutlardan birini oluşturmuştur. 
244 | A. YEMENICI / Din Kültürü ve Ahlak Bilgisi Aday Öğretmenleri ve Danışman Öğretmenlerinin Gözüyle Aday Öğretmen Yetiştirme Eğitimi ve Süreci

Danışman öğretmenlerin atandıkları dönemde, kendi aday öğretmen olma süreçleriyle mevcut aday öğretmen uygulamasına ilişkin yaptıkları karşılaştırmalar, araştırmada belirgin temalardan biridir.

"Bu aday öğretmenler seneye öğretim yılı başlayınca okula gittikleri zaman boş gitmeyecekler. Tecrübeli bir öğretmen olarak başlayacaklar" (KDÖ2).

Uygulama adaylık sürecinde zaman ve enerji kaybını önleyici bir nitelik taşımaktadır.

“Ben kendim yaşayarak gördüm. Mesela bazı konuları nasıl anlatacağımı bilemedim.

Hani sinir ucu konularımız var din ile ilgili...Deneme yanılma yoluyla öğrendik" (KDÖ5).

Başa çıkılması gereken süreçlerden biri adayların, danışmanlarının okullarına aidiyetleri konusunda yaşanmaktadır.

“En eksik ve mustarip olduğum konu, sınıfa iki hoca giriyor. Öğrenciler bana mesela daha sonradan hocam demeye başladılar. [Birlikte derse girmek] tabi ki işe yaradı, hangi perdeden hitap etmek gerektiğini hem gözlemledik hem de zaman içerisinde uygulamaya geçtiğimiz için alıştık da açıcçası" (KAÖ4).

Yukarda (KAÖ4)'ün okula ve sınıfa aidiyet durumu ilerleyen günlerde aşılmakta, ancak bu durumun aşılmasında danışman öğretmenin uygulamadaki yaklaşımı önem arz etmektedir. Danışman öğretmenin sınıfında öğrencilerle kurduğu iyi ilişkiler, adayın öğrenci öğretmen iletişiminde olumlu bir iklimle karşılaşması anlamına gelmektedir.

“Öğrenciler böyle bir paniklediler. Yani hocam bu mu girecek bizim dersimize? Hani onu biraz küçük gördüler. Daha sonra dedik bunlar öğretmenleriniz, aday öğretmen, bu sürece başlıyorlar. Onlara ne kadar güzel örneklik teşkil ederseniz, siz öğrenci olarak biz öğretmen olarak onların hayat çizgilerinde olumlu birtakım katkılarda bulunacağız deyince, bizim öğrenciler zaten çok olgun, yani olayı kavradılar. Ondan sonra sahiplendiler" (KDÖ2).

Diğer önemli nokta sürecin işleyişi ile ilgili adayların belirsizlik algısı içinde olmalarıdır. Özellikle özlük haklarıyla ilgili belirsiz uygulamalar karmaşaya dönüşebilmektedir. Bu süreçte danışmanların tavrı belirleyici olmuştur.

\footnotetext{
"Mesela biz de uzunca bir süre raporu nasıl yazacağımızı bilmiyorduk. Hatta bir dönem raporu yazdık, sonra tekrar silmek zorunda kaldık” (KAÖ1).

“İlk başta bize dediler ki, sanki biz hiç hasta olmayacakmışız gibi siz ne kadar rapor alırsanız ne kadar izin alırsanız, gitmezseniz, sizin o kadar adaylığınızı uzatacağız. Ben
} 
A. YEMENICI / Teacher Candidate Training and Training Process from the Perspective of Religious Culture and Moral Knowledge Teacher Candidates and Adviser Teachers | 245 hasta oldum ateşler içinde okula gittim. Sonra başka okullardan öğrendik, ya müdürle bir şekilde yani izin almak..." (EAÖ3).

"Açık söyleyeyim ben bu aday öğretmenlik sürecini çok gereksiz buldum ilk başta. Yalnızca ben değil diğer bütün aday öğretmen arkadaşlarım da. Ama sonrasında danışman öğretmenimle daha çok kaynaştıkça, verimli olduğunu düşündüm... Özellikle pazartesi günlerini unutamam. Bizim nöbet günümüz. O nöbeti tutarken danışman öğretmenimin çok fazla tecrübelerini dinledim ve çok fazla yardımı oldu bana" (EAÖ3).

Uygulamada danışmanlar mevcut ders yüklerine ek olarak aday ile ilgili ek sorumluluklar üstlendiler. Bu durum, yürütülebilir seviyede tutulmadığında, danışmanlar için verimin düşmesine yol açacak bir isteksizlik ortaya çıkarabilmektedir.

“Aday öğretmenlik sürecinin gözden geçirilmesi taraftarıyım. Çünkü okul ortamında girdiğimiz otuz saat dersin üzerine bize bir de birtakım sorumluluklar yüklendi ki biz o sorumlulukları yüklenirken öbür tarafta birtakım aksamalar söz konusu olabildi." (KDÖ1).

“...Memnunuz. Ama işte bu aksaklık yönleri keşke giderilebilse... Biz bir şeyler yapmaya çalıştık. Gayret ettik... Büyük bir sorumluk verdiler ve karşılığında hiçbir şey yok" (KDÖ2).

Danışman ve aday öğretmenler uygulamanın özünü etkilemeyen şekilsel uygulamaları elimine edebilecekleri bir değerlendirme ortamı istemektedirler.

"Rehberlik yapma açısından insan bundan memnun kalır. Ama işin formalite kısmı var...kırtasiye işini kaldırırsak bu iş olabilir" (EDÖ3)

"Biz bu süreçte bunu nasıl yazsam şunu nasıl rapor etsem? Hep kafa onlarla yoruldu. Hiç işlevsel olmuyor bu raporlama süreci. Kalın kalın dosyalar oluşturduk. Yoksa kendini de masaya yatırma sürecin olmuyor, biz bu masaya yatırma sürecini bu dokümanlar yüzünden çok fazla yaşayamadık" (KAÖ1).

Uygulamada okul yönetiminin üzerine düşen görevleri yerine getirdiği ve aday öğretmenlerin süreçte okul yönetiminden gerekli desteği gördükleri ortaya çıkmıştır. Ancak, adayların bazı girişimlerinde çekimser davranan okul yönetimleri de olmuştur.

"Bir istekle gittiğiniz zaman, sorumluluk almak istememe, ben bunu yapamam, bunu yapamazsınız. Kendinizi ifade etmenize rağmen karşıdaki kişi sanki siz ondan yasal olmayan bir şey istiyormuşsunuz gibi size muamele yapabiliyor" (KAÖ5). 
246 | A. YEMENICI / Din Kültürü ve Ahlak Bilgisi Aday Öğretmenleri ve Danışman Öğretmenlerinin Gözüyle Aday Öğretmen Yetiştirme Eğitimi ve Süreci

“Bizim okul müdürümüz gerçekten çok iyiydi. İdareciyle öğretmen arasındaki ilişkiyi çok güzel kuran, her konuda yardım sağlayan, bir de böyle sizi kısıtlamıyor, bir sosyal proje oluyor mesela direkt atliyor. Destek veriyor, maddiyattan kaçmıyor. Önemli olanın oraya aktif olarak katılım olduğunu savunan bir insandı. Diğer idarecilerimiz, müdür yardımcılarımız da öyleydi. Ben onları çok özleyeceğim" (KAÖ1).

\subsection{Bir Öğretmen Nasıl ve Ne zaman Mutlu Olabilir?}

Aday öğretmen - danışman öğretmen uygulamasında aday öğretmen kendini görmek istemekte, nasıl bir başlangıç yaptığını merak etmekte ve nasıl ilerleyeceğini kestirmek arzusu içinde olmaktadır. Kendini göremediğinde de huzursuzluk yaşayabilmektedir. Bu durum, adayın mesleğe bağlanmasında göz ardı edilemeyecek bir etken olarak görünmektedir. Adaya verilecek bildirimler kendini yapılandırmasını sağlamaktadır. Aday öğretmenin mutlu olmasında, danışmanından, öğrencilerden ve çevreden gelen dönütler büyük bir etki göstermiştir.

“Genel olarak okul motive ediciydi. Hani danışmanımın, öğrencilerin tavırları, benden bir şeyler öğrenmiş olmaları, bir şeyler katabilmiş olmak, yapabilmek, anlatabilmek motive ediciydi. Ama genel süreç olarak değerlendirdiğimizde bu süreci koordine eden kişiler tarafından görmüş olduğumuz tavır bambaşka... Gelmeye mecbursunuz gibisinden bir üslup kullanıldı. Benim soğuduğum dönemler oldu öğretmenlikten. Tam bir öğretmen olarak görülmediğimizi görünce, düşünmeye başlayınca. Ama okul içerisinde motivasyonum artıyordu tabii ki. Hani öğrencilerden karşılığını aldıkça" (KAÖ2).

“İlk üç gün konu anlatırken anlatacağım şeyi unutuyordum, biraz pasiftim derste, o yüzden hani korkuyordum. Teneffüslerde hocamla konuşurken; tamam şimdi bu dört dörtlük değil ama bu düzelecek, ilerleyecek, bu şu an için çok yeterli diyordu. Hocam öyle dedikçe benim isteğim arttı, isteğim arttıkça kendimi daha güzel ifade edebildiğimi gördüm. Teneffüslerde öğrencilerden aldığım tepkiler...Diyorum ki; "vay be demek ki anlatabiliyormuşum". Bunlar beni çok motive etti, ben belki danışmanımı sevmeseydim bu kadar yol kat edemezdim adaylık sürecinde" (EAÖ3).

Uygulamada danışmanlar da yaptıklarının nasıl bir karşılık bulduğunu anlamak istemektedirler. Adaylarda gözlemledikleri başarılı bir değişim, adaylardan ya da yöneticilerden gelen her türlü geri bildirim onları motive etmekte ve onların mutlu olmalarını sağlamaktadır.

“Kendimizi de görmemizi sağladı. Böyle bir çalışmaya katkıda bulunduğum için çok mutlu oldum. Keşke bunu, bu çalışmayı yapanlara da rapor olarak gönderebilseydik.

... Bir teşekkür belgesi gönderseydi...bir plaket verilseydi... Parasal yönü 
A. YEMENICİ / Teacher Candidate Training and Training Process from the Perspective of Religious Culture and Moral Knowledge Teacher Candidates and Adviser Teachers | 247 ayrı...Manevi takdiri de böyle hissettirilseydi değil mi? Değerli olduğumuz hissettirilseydi" (KDÖ3).

“Öncelikle ben sana teşekkür ediyorum. Yaklaşık bir buçuk iki saattir içimizi döküyoruz. Ne kadar çok anlatacak şeyimiz varmış. Oysa bu çalışmayı milli eğitimin de yapması lazım" (KDÖ2).

“Sadece bir tek başlangıçta müdürün onayı vardı, bir de sonuçta. Onun dışında her şey sadece benim imzamla yapılıyor olması beni çok mutlu etti...İnisiyatifim var, bana değer veriliyor diye..." (KDÖ3).

“Aday öğretmen yetiştirme konusu en azından beni heyecanlandırdı, dedim ki herhalde öğretmenlik bir yerden tutup kaldırılacak..." (EDÖ4).

"Motivasyonumuz artıyor aday öğretmen yetiştirme sürecinde. Artık tecrübeli, deneyimli,... yetenekli görünüyoruz"(EDÖ1).

\subsection{Alan - Saha ilişkisi ve Formasyon Eğitimi}

Alan saha ilişkisi ve formasyon eğitimi, fakülte yıllarında edinilen birikiminin fakülte dışına transfer edilmesi, bu transferin öğretmen için

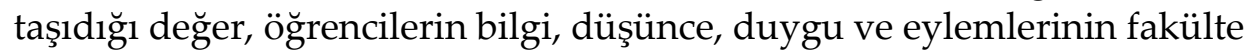
yıllarında edinilen birikimle irtibatlandırılma biçimi olarak anlam kazanmıştır.

Adayların ve danışmanların deneyimlerine göre fakülte lisans eğitimi içinde ya da dişardan formasyon sertifikası kapsamında yapılan öğretmenlik uygulamaları ile bu araştırmada konu edilen aday öğretmen uygulaması arasındaki farklar temalardan birini oluşturmaktadır.

“Biz formasyon aldık, ama yani fazla da önem vermedik. O kadar fazla ciddi olmadı.

Teorik bölümü branşla ilgili olmadığı, genel eğitim dersleriyle ilgili olduğu için..." (EAÖ2).

"Fakültedeki staj hani biraz daha buna [Aday öğretmenlik uygulamasına] göre light geçiyor" (EAÖ1). [Bu kıyaslamayı yapan EAÖ1, Eğitim Fakültesi DKAB bölümü mezunudur.]

“Bu lisans sonrasından pedagojik formasyon alan bir öğrenci grubu geldi. 6 kişi vardı. Bir tanesi hariç diğerleri laf olsun diye yaptılar. Yani çok sıkıştırılmış bir şeydi" (KDÖ5).

Adaylar bu uygulamada, stajyerlik ve adaylik arasında kalma gibi bir tereddüt yaşamaktadırlar. Bu tereddüdün ancak sınıfta öğrencinin karşısına çıkılarak yaşanan gerçek bir öğretmenlik deneyimiyle aşıldığ görülmektedir. 
248 | A. YEMENICİ / Din Kültürü ve Ahlak Bilgisi Aday Öğretmenleri ve Danışman Öğretmenlerinin Gözüyle Aday Öğretmen Yetiştirme Eğitimi ve Süreci

“Yaşayarak öğreniyorsun gerçekten birçok şeyi. O sınıf senin olduğu zaman gerçekten tecrübe edinmeye başliyorsun" (KAÖ1).

“Bize genelde stajyer gözüyle bakıldı. Öğrenci gözüyle bakıldı ki biz bunu tamamladık, atamamız gerçekleşti. Bu da tabii ilk başlarda öğretmenin özgüvenini sarsıcı mahiyette gelişiyor. Nasıl davranmamız gerekiyor? Tam öğretmen gibi mi davranacağız? Yoksa eğitim gören bir öğrenci gözüyle mi davranacağız" (EAÖ1)

“Korkuyordum yani açıkçası. Ders anlatmaya başlayınca aklıma konuyla ilgili ayet geliyor, hadis geliyor, diyorum ki: Vay be! Bende varmış bir şeyler. Sonraki günlerde yine hocam dedi işte çok güzel...bir de öğrencilerden aldığım tepkiler, ondan sonra alıştım sevdim. Dediğim gibi bırakmayı düşünüyorken 5 sene sonra, şimdi asla diyorum” (EAÖ3).

İlahiyat alanında özel öğretim yöntemleri için ihtiyaçların dile getirildiği görülmektedir.

“Tespit etmeye başladığım andan itibaren çok faydalı oldu. Çocuk neden hoşlanır? Hoşlandığı derken hani çocuğun ilgisi, merakı, seviyesine uygun gidince mesela onun daha çok ben farkına vardım. Bize bunun eğitimi çok az veriliyor" (KDÖ4).

“Az önce çok felsefi görüyoruz dedim ama mesela işin ilginç tarafı derslerde daha çok felsefi şeyler söylemeyi tercih ettim. Özellikle çocukların bilimsel şeyler böyle felsefi şeyler çok dikkatlerini çekebiliyor. Açıkçası felsefe dersi almanın verdiği bir avantaj oldu." (KAÖ3).

İlahiyat alan bilgisi ile öğrencinin ilgi ve ihtiyacının hangi bağlamlarda ve düzeyde ilişkilendirileceği konusunda adaylar tereddütler yaşamaktadır. Adaylar adeta alan bilgisinin derinliği ile öğrencinin talep ettiği arasında kestirilemeyen öğrenci soruları ve ilgi düzeyleri karşısında bocalama içindedirler. Fakültede alınan bilgilerin fakülte dışında hayata aktarılmasından, aynı bilgiyi dışarda da kullanmak anlaşılmakta, bu mümkün kılınamayınca da gündelik hayatla akademik bilgi arasında bir ayrışma sorunu varmış gibi bir algı ortaya çıktığı görülmektedir.

“Yani biraz bizim hayatla bağlantılı değil de biraz daha düşünsel, felsefi açıdan verildiği için üniversitedeki eğitim biraz daha akademik. Orada öğrendiğiniz bilgileri bırakın öğrencilere anlatmayı, halktan herhangi bir insana bile anlatamıyorsunuz. Yani pratiğe dökemiyorsunuz bilgilerinizi. Onlar sizin kafanızın içinde dönüp duruyor (KAÖ3)."

“Hayatın gerçekleriyle hiç eğitim almadık. Alan dersleri hakikaten insanlara kendini yetiştirecek düzeyde veriliyor. Bunu kabul etmemiz lazım.., yani epeyi kitap okumuşsunuz. Okutuyorlar zaten. Buraya [okula] geliyorsunuz, kitapların içeriği boş, 
A. YEMENICİ / Teacher Candidate Training and Training Process from the Perspective of Religious Culture and Moral Knowledge Teacher Candidates and Adviser Teachers | 249 hep ortaokulda ders verdiğimiz için kitaplarda çiçekten böcekten bahsediyor. Müfredatımız biraz o konuda hafif. O zaman da unutuyorsunuz... (EAÖ2)."

(EAÖ2) deneyiminde akademik bilgilerin öğrenci seviyesine indirilmesindeki sorunun aşıldığ 1 belirtiliyor, ancak kitapların ve müfredatın çok basit olduğu ileri sürülüyor. Bu durum öğrencinin seviyesine karşılık gelen bilginin, aday tarafından bir anlam ifade etmediği, öğrenci seviyesinin bir algıya karşılık gelen bir fenomen değil de, gelip geçici bir durum olduğu ve ders anlatırken o seviyeye inilip sonra tekrar kendi normal seviyesine çıkılacağı şeklinde gelip geçici bir transfer biçimi benimseniyor. Ders konusu olan ilahiyat alanındaki bir bilginin öğrenci seviyesinde neye karşıllk geldiğinin değeri ve anlamı kaybolduğunda, dersin konusu, kitap, öğretim programı, yöntem ve öğrenci öğretmen ilişkisi gibi temel bileşenler arasındaki bağ zayıflıyor.

“Formasyonu sonradan aldım, bir sene içerisinde. Çok faydalı oldu, öğrencilere karşı nasıl davranmam gerektiği hakkında, mesela sunum hazırladım, sunumu bile formasyonda öğrettiler. Öğretmeselerdi yapamayacaktım...Alan dersleri işte dedim ya çok şey bilmek gerekiyor. Tamam, öğrenci seviyesi diyoruz ama yani kitabın dili çok basit ama onlara anlatmak için bile çok şey bilmek gerekiyor. Ben anlatırken adaylık sürecinde olduğum için anlatıp geçiyordum, sadece kitaba bağlı kalıyordum, ama ilerleyen zamanlarda sadece alan derslerinin yeterli olmayacağı düşüncesindeyim. Kendimi bayağ1 geliştirmem gerekiyor" (EAÖ3).

“Öğrenci soruları bazen zorladı beni öyle söyleyeyim. Farklı şeyler bilmek gerekiyor, sadece ilahiyatta aldığımız yetmiyor. Din kültürü dersinde her soruya sadece dini açıdan cevap vermem gerekiyor gibi düşünüyordum ilk başta, o yüzden ben direkt ilahiyatta ne öğrendim diye hemen onu düşünmeye çalışıyordum. Ama sonrasında zaman geçtikçe son haftalarda özellikle farklı olarak da düşünmeye başladım, daha bilimsel yaklaşmaya çalıştım. Mesela filozofların sözlerinden bile cevap vermeye başladım” (EAÖ3).

Öğretmenler; hem derse hem de kendilerine yönelik farklı meslektaşlarından, velilerden, öğrencilerden, toplumdan gelen beklentiler ve din konusundaki farklı algılama biçimleri karşısında zorluklar yaşamaktadırlar. Başarılı örneklere bakıldığında, iletişim bakımından sorun yaşamayan, mesleği, okulu ve sınıfı ile barışık olan öğretmen deneyimlerinin öne çıtı̆̆ 1 görülmektedir.

“Zihinsel anlamda inanç düzeyinde karma sınıflar. Ateistinden tut çok dindar aile çocukları bir arada. Dolayısıyla hepsine, her kesime hitap edecek bir konuşma dili 
250 | A. YEMENİĊ / Din Kültürü ve Ahlak Bilgisi Aday Öğretmenleri ve Danışman Öğretmenlerinin Gözüyle Aday Öğretmen Yetiştirme Eğitimi ve Süreci

geliştirmemiz gerekiyor. Bunu biz yıllar içinde zaten geliştirdik ama aday öğretmenler bu süreci çok iyi bilmiyorlar. Yani konuşurken sanki camide vaaz eder gibi ilahiyatta yetiştiği ortamda konuşuyor. O adaptasyonda biraz sıkıntı yaşadık" (KDÖ2).

"Veliler de bile benim çocuğum yazın Kur'an kursuna gidiyor. Neden düşük aldı dersten? Hep bir beklenti var" (KDÖ5).

"İlk gittiğimde hatta kendi stajyer arkadaşlarım bile ilahiyat fakültesi olup da oradan din kültürü diye atanıldığını bilmiyorlarmış. İnanılmaz ön yargılar" (KAÖ5).

“[Din kültürü özelinde] Hiçbir zorluk yok. Ben hiçbir zorluk yaşamadım. Zaten okulumda benim öğretmenler, arkadaşlarımla iletişimim güçlü. Yani o da aday öğretmenimin dikkatini çekti..."(KDÖ3).

Adaylar ilahiyat alanı olarak DKAB dersinde kaynak, materyal ve ders işleniş zenginliği anlamında bir yoksunluk duygusu içinde kendilerini görüyorlar. Ayrıca öğretmenin rolü konusunda da konu, muhteva, ders işleniş süreçleri gibi hususlarda pasif bir alg1 geliştirmiş görünmektedirler. Diğer alanların ise ne yaptıklarını bildiklerini ve zengin ders içeriklerine sahip olduklarını ileri sürmektedirler.

“Yeterli kaynağımız yok bizim. Mesela diğer branşlara baktığımız zaman dersin başında sonunda ne yapacaklarını biliyorlar. Bizim ki tamamen afaki yani. İçerik boş bizde, kaynak eksik. Nasıl öğreteceğinizi, nasıl dolduracağınıza siz karar veriyorsunuz. Slaydı ben kendim yaptım. Mesela videodur vesairedir ben kendim ayarlayarak devam ettirdim... Bir İngilizceye baktığım zaman tüm içerik hazır,...tıkır tıkır her şeyi rahat bir şekilde yapıyor...Sadece ezberlemişiz, mesela bir şeyleri sadece öğrenmişiz, ama sınav için çalışmışım ben onu fark ettim okula geldiğim zaman...Hayatın içerisine çok fazla dökememişim, bazı şeyleri pratikleştirememişim" (KAÖ1).

\section{Tartışma, Sonuç ve Öneriler}

\section{1. Öğretmen olmak}

Araştırma bulgularında ortaya çıkan boyutlarından biri öğretmen olmanın anlamı üzerinde yoğunlaşmaktadır. Özellikle öğretmenlerin kişilik özellikleri üzerinde yoğun betimlemeler yapılmıştır. Öğretmen olmaya karar verme süreçlerinde öğretmenlerin kişilik özelliklerinin etkisi açıkça görülmektedir. Bu durum, öğretmen eğitimi süreçlerinde "öğretmenlik yapma" ile "öğretmen olma" kavramsallaştırması üzerinden incelenmektedir (Karadağ - Dulay, 2017).

"Öğretmen olmak" ve "öğretmenlik yapmak" şöyle ifade edilmiştir: Öğretmen olmak; yıllarca unutulmayan ve öğrencilerde derin izler bırakan özelliklere sahip olmak, belirlenmiş görevlerin ötesine geçip 
A. YEMENICI / Teacher Candidate Training and Training Process from the Perspective of Religious Culture and Moral Knowledge Teacher Candidates and Adviser Teachers | 251 mesleğini sevmek, mesleğinin gerektirdiği özverinin farkında olmak, öğretim yaklaşımlarını öğrencilerini ve onların ihtiyaçlarını gözlemleyerek oluşturmak, temelde öğrencilerle sevgi saygı ve güvene dayalı ilişkiler kurmak olarak açıklanmış, öğretmenlik yapmak ise sadece belirlenmiş ve tanımlanmış görevlerle sınırlandırılmış bir anlayış olarak belirlenmiştir (Karadağ - Dulay, 2017, 387).

Din eğitimi alanındaki aday ve danışman öğretmen deneyimleri üzerinden öğretmen olmanın anlamına yönelik kişilik özellikleri dikkate alındığında, araştırma bulgularından aşağıdaki sonuçlara varmak mümkündür.

Öğretmen olmaya karar vermede etkili olan nitelikler: İnsanlara bir şeyler öğretme arzusu içinde olmak, insan yetiştirmenin değerini $\mathrm{Hz}$. Muhammed üzerinden, O'nun insanlarda ve toplumda bıraktığı etkiyi okul ve sınıf örnekliğinde gösterebilmek, saygilı ve kibar davranan bir öğretmen olarak öğrencinin karşısına çıkmak, "acaba sevdiğim öğretmenim nasıl anlatıyordu" diye öğrencilerinin hafızasında bir model olmayı başarmak, disiplini ve şefkatli kişiliği ile işini ve mesleğini seven, sevdiğini de hissettiren ve bunu nasıl başardığı konusunda da öğrencilerinin zihninde merak duygusu uyandırarak yer edinmek, öğrenciyi derse katan ve dersle bütünleşmiş bir şekilde yaşayarak dersi anlatabilmek, öğrenciyi dinlemek, değer verdiğini öğrenciye hissettirmek, öğrenciye umut aşılamak ve zorluklar karşısında motive etmek. Bu nitelikler, bir öğretmeni öğretmenlik yapmaktan öğretmen olmaya taşıyan özellikler olarak anlam kazanmıştır.

Tartışma ve sonuçlardan hareketle şu öneriler üzerinde durulabilir:

İlk defa denenen uygulama, aksaklıklar giderilerek en kritik aşamalarından birini oluşturan adaylık eğitimi süreçlerinde tekrar yürürlüğe konabilir. Böylece aday öğretmenler atanır atanmaz sadece "öğretmenlik yapmak" için acilen derslere girmek zorunda kalmayacak, öğretmen olmayı başarmış danışmanın yanında "öğretmenlik yapmaktan öğretmen olmaya" nasıl bir dönüşüm yaşandığını deneyimleme imkânına kavuşmuş olacaklardır. 
252 | A. YEMENICİ / Din Kültürü ve Ahlak Bilgisi Aday Öğretmenleri ve Danışman Öğretmenlerinin Gözüyle Aday Öğretmen Yetiştirme Eğitimi ve Süreci

\section{2. Öğrenmenin ve Öğretmenin Yeniden Keşfi: Adaylık ve Danışmanlık}

Günümüzde yaşanan hızlı ve yoğun değişim dikkate alındığında, öğretmenlerin öğrenme ortamlarında yaşadıkları zorlukların neleri talep ettiği çok yönlü yaklaşımları kaçınılmaz kılmaktadır. Süreç, öğretmenlerin hizmet öncesinde yetiştirilmesi kadar içinde bulundukları ve yüzleştikleri gerçekliği dikkate alan mesleki gelişim boyutunun da farkında olan arayışları zorunlu hale getirmektedir. Bu bağlamda pek çok yaklaşım ve arayış üzerinde durulmaktadır (Güneş, 2016, 415).

Özellikle iki temel yaklaşıma dikkat çekmekte fayda vardır. İlk yaklaşımda öğretmen eğitiminin sadece yetiştirme boyutu üzerinde durulur, mesleki gelişimine gereken ehemmiyet verilmez; oysa diğer öğretmen eğitimi yaklaşımında mesleki gelişim tam da öğretmenin kendi, öğretme ortam ve uygulamalarının bir bileşenidir ve öğretmen kendi bilgisini kuramsal ve uygulama boyutuyla geliştirmeye açık tutar (Atay, 2003, 51).

Farklı ülkelerde aday öğretmen eğitimi ve danışman öğretmenlerin süreçte aldıkları görevin işlevi üzerinde durulmakta, özellikle adayların göreve başladıkları çok erken bir zamanda ayrılıyor olmaları, hatta deneyimli öğretmenlerin tüm birikimleriyle mesleği bırakmaları, öğretmen eğitimi sisteminin temel sorunlarından biri olarak görülmektedir (Darlink - Hammond, 2016, 117). Bu sorun çerçevesinde yapılan araştırmalarda, adaylık eğitiminde danışmanlık (mentörlük) sisteminin etkisine dikkat çekilmekte, iyi tasarlanmış mentörlük programlarının öğretmenlerin tutumlarını ve mesleki becerilerini geliştirerek adaylar için görevde kalma oranını artırdığı, deneme yanılma ile adaylık sürecini geçiren öğretmelere kıyasla daha kısa sürede uzmanlaştıklarını, aynı şekilde kıdemli öğretmenlerin de yeni bir soluk kazandıkları, adaylara deneyimleriyle rehberlik yapmanın yanı sira meslekte daha uzun süre kalmalarını sağladığ - Hammond, 2016, 118).

Farklı çalışmalarda, ülkemizdeki yeni uygulamanın adayların eğitim süreçlerine katkı yaptığı yönündeki bulgular, bizim çalışmamızla örtüşmektedir (Sarıkaya vd., 2017, 939; Kozikoğlu - Soyalp, 2018, 934; Ulubey, 2018, 480; Cengiz, 2018, 932). Çalışmamızda diğer çalışmalardan farklı olan bulgu ise, aday eğitiminin aynı zamanda danışman 
A. YEMENICI / Teacher Candidate Training and Training Process from the Perspective of Religious Culture and Moral Knowledge Teacher Candidates and Adviser Teachers | 253 öğretmenlerin mesleki gelişimleri açısından da katkı yaptığı yönünde olmuştur.

Öğretmen eğitimine bir bütünlük içinde bakıldığında, araştırma bulgularından ve tartışmalardan aşağıdaki sonuçlara varmak mümkündür:

Ülkemizde bir kez denenmiş olan aday öğretmen eğitimi hem adaylara yönelik mesleğe başalarken hem de danışmanların mesleki gelişimleri açısından öğretici ve destekleyici bir işlev görmüş, adaylar ve danışmanlar arasında etkileşim ortamı oluşturmuştur.

Yeni uygulama, aksayan yönlerine rağmen adayları kritik geçiş sürecinde daha hazırlıklı hale getirmiş, danışmaları da mesleki gelişimleri bakımından sisteme daha aktif bir şekilde katabilmiştir.

Danışman öğretmenlere, uygulama öncesinde verilen eğitimler destekleyici bulunmuştur. Ancak bu eğitimlerin eğiticiler, ortam, içerik, zaman ve danışmanların sürece katılma biçimlerine göre verimlilik durumları değişkenlik göstermiştir.

Tartışma ve sonuçlardan hareketle aşağıdaki öneriler üzerinde durulabilir.

Aday öğretmenler çoğu zaman dolu olan merkezi okullara gelebilme ve okulların kurum kültüründen yararlanma imkânından meslek hayatlarında uzun süre mahrum kalmaktadırlar. Yeni başlayan aday öğretmenler için bu engelleyici durumu ortadan kaldırmanın bir yolu olarak, incelenen uygulamada olduğu üzere aday öğretmenliğin ilk altı ayında atandıkları okullarda direk derse girmeden ve deneme yanılma süreçlerine maruz kalmadan, merkezi okullarda ve danışman öğretmenlerin rehberliğinde göreve başlamaları sağlanabilir.

Aday öğretmen eğitimi için danışman (mentör) öğretmenlere ve koordinatörlere verilen eğitimlerde ortam, amaçlar, temel konular, zaman ve eğitici gibi bileşenlerin tüm gruplar için eşit bir program çerçevesinde yürütülmesi sağlanabilir.

Lisans döneminde inanç/kültür farklılığını ve öğretim yaklaşımlarını konu alan seçmeli derslere programlarda daha etkin bir şekilde yer verilebilir. 
254 | A. YEMENICİ / Din Kültürü ve Ahlak Bilgisi Aday Öğretmenleri ve Danışman Öğretmenlerinin Gözüyle Aday Öğretmen Yetiştirme Eğitimi ve Süreci

\subsection{Aday Öğretmen Danışman Öğretmen Uygulaması ve İşleyişi}

Aday öğretmen eğitiminde benimsenen model ve programların daha işlevsel hale gelmesi için yeterli veri setini oluşturabilmek önem arz etmektedir (Ingersoll, 2016; K. Wong vd., 2016). Bu bağlamda farklı ülke deneyimlerinde adaylık programlarının verimli olması için bazı etkenler üzerinde durulmaktadır. Aday öğretmenlik programlarının kapsamlı tutulması, adaylar için azaltılmış ders yükü, aynı branştan öğretmenlerden planlama ve danışmalık desteği almak gibi bileşenler ön plana çıkmaktadır (Ingersoll, 2016, 266).

Ülkemizde de ilk defa uygulanan adaylık programı, diğer uygulamalarla kıyaslandığında adaylar için ilk dönem ders yükü getirmemesi ve yoğun danışman desteği sunması bakımından işlevsel olduğu araştırma bulgularında görülmüştür.

Aday öğretmen eğitimiyle ilgili iş ve işlemleri konu alan farklı çalışmalarda da aşağıdaki bulgular üzerinde durulmuştur.

Uygulama pek çok yönden olumlu bulunmakla birlikte evrak yoğunluğunun fazla olması yakınma konusu olmuş, aday öğretmenlerin tamamı kitap okuma, film izleme ve yapılan ziyaretleri olumlu bulmakla birlikte önerilen kitaplar okunduktan sonra özet yazmak zorunda bırakılmalarına anlam verememiştir (Topsakal - Duysak, 2017, 629 - 630). Özlük hakları bakımından süreçte emeği geçenlere belirli ödemelerin yapılmasının güdülenmeyi arttıracağı üzerinde durulmuştur (Topsakal Duysak, 632). Programın olumlu yönlerine rağmen paydaşlar tarafından anlaşılamamasından kaynaklı sorunların yaşandığı, programın uygulanması ve denetiminde de sorunlar olduğu belirtilmiştir (Ulubey, 2018, 485). Okul içi, okul dışı ve hizmet içi eğitim faaliyetlerinin yüksek oranda gerçekleştirildiği ifade edilmiş, süreçte bilgilendirme yetersizliği, aday öğretmenlerin okulda kendilerini değersiz hissetmeleri gibi konular aday öğretmenler tarafından çoğunlukla sorun olarak görülmüştür (Alataş, 2017).

Uygulamanın işleyişi ile ilgili hem bizim araştırmamız hem de diğer çalışmalardan hareketle aşağıdaki sonuçlar üzerinde durulabilir.

Söz konusu uygulama, mesleğin kritik aşamasında adayları doğrudan derse sokmayarak yoğun gelebilecek ders yükü karşısında daha hazırlıklı olmalarını sağlamıştır. Hem adaylar hem de danışmanlar bu durumu olumlu karşılamışlardır. Farklı ülke deneyimlerinde de yeni 
A. YEMENICI / Teacher Candidate Training and Training Process from the Perspective of Religious Culture and Moral Knowledge Teacher Candidates and Adviser Teachers I 255 başlayanlar için bu durum odak konulardan biri olarak ele alınmaktadır. Öğretmenlik mesleğinin sınıf gerçeğinde çoğu zaman diğer meslektaşlardan izole bir şekilde gerçekleştiği belirtilmekte ve bu izolasyonun getirdiği yalnızlık ve zorluk özellikle yeni başlayanlar için "denizde kaybol, bat ya da çı, ateşle oynamak, ya da gençleri parçalayan bir meslek olarak öğretmenlik" gibi ifadelerle tartışma konusu edilmektedir (Ingersoll, 2016, 261). Bu çerçevede yeni uygulamanın adaylık sürecindeki pek çok mesleki zorluğu giderdiği söylenebilir.

Aday öğretmen programına yönelik bir kez denenen bu uygulamaya ilişkin elde edilen veriler alanda bir canlılık oluşturmuş ve öğretmen eğitimine yönelik ülkemizde yeni bir bakış açısı kazandırmıştır. Adaylık eğitiminde aşırı derecede form doldurma, raporlama ve kırtasiye işlemleri, uygulamanın özüne katkı yapmayan bir iş yükü olmanın ötesinde bir anlam taşımamıştır.

Bazı adayların, danışmalarının okullarına karşı ilk haftalarda aidiyet konusunda zorluklar yaşadıkları görülmüştür. Ancak bu durum danışmanların, okul idaresinin ve ilerleyen haftalarda öğrencilerin yaklaşımlarına göre değişiklik göstermiştir. Çoğu örnekte iyi yönde ilerleme olmuştur.

Özlük hakları ile ilgili belirsiz işlemler, programın verimini olumsuz etkilemiştir. Özellikle stajyerlikte uygulama öğrencileri için uygulama öğretmenlerine ödenen ücretin, aday öğretmen eğitimi sürecinde danışmanlar için verilmemesi çelişkili bir durum olarak görülmüştür.

Alanında başarılı ve okulda iletişimi iyi olan danışmaların uygulamada yer alması, özellikle ilahiyat alanında DKAB adayları için diğer branşlardan meslektaşları, sınıf ve veli iletişimi açısından işlevsel bulunmuştur.

Bu sonuçlardan hareketle aşağıdaki öneriler üzerinde durulabilir.

Diğer uygulamalardan farklı olarak bu yeni uygulamada işlevsel hale gelen, atandıkları ilk dönemde adayların yalnız başına derse girmeme ve nöbet tutmama görevi aday öğretmen eğitiminde devam ettirilebilir. 
256 | A. YEMENICİ / Din Kültürü ve Ahlak Bilgisi Aday Öğretmenleri ve Danışman Öğretmenlerinin Gözüyle Aday Öğretmen Yetiştirme Eğitimi ve Süreci

Adayların adaylık süreçlerinde hem çalıştıkları okula hem de bakanlığın tüm diğer birimlerine aidiyet duygusu kazanmaları konusunda gerekli etkinliklere ağırlık verilebilir.

Uygulamanın özünü değiştirmeyecek sayı ve yoğunluktaki form doldurma ve kırtasiye işlemleri azaltılabilir.

Aday eğitiminde danışman öğretmenlerin özlük hakları, çalışma saatleri, ücretlendirilmeleri ve iş yükleri dikkate alınarak düzenlemeler yapılabilir, danışmanlık için teşvik edici dönütler verilebilir.

Gönüllülük esasının danışman öğretmenlerin seçilmesinde işlevsel olması sağlanabilir.

Adaylık süreçlerinde verimli okul iklimi oluşturan yöneticiler onure edilebilir.

\subsection{Bir Öğretmen Nasıl ve Ne Zaman Mutlu Olabilir?}

Aday eğitimi sürecinde adayların ve danışmanların duygu, değer ve anlam dünyasında neler deneyimlenmiştir ve öğretmenler için bu deneyimler ne anlama gelmektedir? sorusu, uygulama boyunca belirgin boyutlardan bir diğerini oluşturmuştur.

Literatüre bakıldığında öğretmenlerin, iş yaşamındaki motivasyonları, mesleki değerleri, mesleğin icrasında elde edeceği doyum, yaşayacağı mutluluk ve anlamlı çalışma gibi bireyin psikolojik ihtiyaçları belirgin eksenleri oluşturmaktadır (Çetin, 2018, 171).

Aday öğretmen olma süreci ve uygulamalarına ilişkin yapılan çalışmalarda, duyguların öğretmenlik mesleğinin güçlü yanlarından birini oluşturduğu, öğretmene atfedilen önem ve öğrenme - öğretme çabasında başta adaylar olmak üzere öğretmenlerin hak ettiği değeri görüp görmeyeceği endişesi, gönüllü dahi olsa gerçekleştirilen çalışmaların kalitesini etkilediği üzerinde durulmaktadır (Kılıç ve Özbey, 2016, 35).

$\mathrm{Bu}$ anlamda öğretmenin kim olduğunu bilmesi, iyi bir öğretim için en az öğretilecek konu ve öğrenci kadar değerli ve önemli görülmekte, bu öncüllerden hareketle iyi bir öğretimin ortaya konması için öğretmenin hayatında kendine yönelik daha derin bir çerçeve oluşturacak alanlar açılmasının imkânına vurgu yapılmaktadır (Palmer, 2016, 58).

Araştırma bulgularından ve tartışmalardan hareketle öğretmenlerin duyuşsal ihtiyaçları ile ilgili olarak aşağıdaki sonuçlar üzerinde durulabilir. 
A. YEMENICI / Teacher Candidate Training and Training Process from the Perspective of Religious Culture and Moral Knowledge Teacher Candidates and Adviser Teachers | 257

Yeni uygulamanın getirdiği bir fırsat olarak öncelikle adayların ve danışmanların birbirlerine verdikleri dönütler, öğrencilerden, velilerden ve çevreden aldıkları tepkiler, gördükleri ilgi, üst birimler nezdinde taşıdıkları değer, öğretim süreçlerinde kim olduklarını daha da güçlü bir şekilde anlamlandırmalarını sağlayan etkenler olarak görülmüsstür.

Özellikle öğretmenliğin yeniden ayağa kaldırılmasında güzel, verimli bir uygulama hissini uyandırdığı, dışardan bakılınca artık deneyimli öğretmen olarak görülmenin; imzasına ve inisiyatifine güvenilerek danışman seçilmenin, bir öğretmenin kendini yeniden değerlendirme anlamında başlı başına bir değer taşıdığı ortaya çıkmıştır.

Uygulamadaki yoğun koşuşturmaların, bir plaket ya da ücret olarak karşılığının takdir edilmemesi çok üzücü karşılanmıştır.

Aday eğitimi süreci, hem adaylar hem de danışmanlar için meslek hayatında unutulmayacak çok hoş ve değerli bir anı olarak anlamlandırılmıştır.

Deneyimlerini anlatmalarına ve içlerini dökmelerine fırsat vermesi nedeniyle bu tür nitel araştırma görüşmeleri çok değerli bulunmuştur.

Genç aday öğretmenlerle bir dönem boyunca yoğun deneyim paylaşımı, danışmanlar için taze kan gibi yenileyici bir anlam taşımıştır.

Yukardaki sonuçlardan hareketle aşağıdaki öneriler üzerinde durulabilir:

Mesleki gelişim seminerleri ve müfettişlerin rehberlik çalışmaları, özellikle öğretmenlerin ihtiyaçları ve önerileri çerçevesinde daha işlevsel hale getirilebilir.

Aday eğitiminde sürece gönüllü olarak katılan ve uygulamalarda aktif görev alan danışman öğretmenler plaket (onurluk) ve ek ücret ile takdir edilebilir.

\subsection{Alan Saha İlişkisi ve Formasyon Eğitimi}

Alan saha ilişkisi ve formasyon süreci hem hizmet öncesi hem de hizmet içi boyutları ile ilahiyat alanına bağlı öğretmenlikler açısından pek çok araştırmaya ve tartışmaya konu olmaktadır.

En belirgin tartışmalardan biri formasyon eğitimi üzerinde yapılmaktadır. Sertifika şeklinde yürütülen formasyon eğitiminin lisans içinde alınan formasyon eğitimine, özellikle bu çalışmada incelenen 
258 | A. YEMENICİ / Din Kültürü ve Ahlak Bilgisi Aday Öğretmenleri ve Danışman Öğretmenlerinin Gözüyle Aday Öğretmen Yetiştirme Eğitimi ve Süreci

adaylık eğitimi süreçlerine kıyasla pek çok açıdan yetersiz olduğu ifade edilmektedir.

Çınar (2016, 493)'ın çalışmasında öğretmenlik formasyon derslerinin lisans eğitimi içerisinde verilmesinin, sertifika programı şeklinde verilmesine kıyasla, öğretmen adaylarının öğretmenlik tutum ve yeterliklerinde ve tüm alt boyutlarında (DKAB bölümü lehine) anlamlı düzeyde farkl1lık oluşturduğu belirtilmiştir. Gün $(2017,125)$ 'ün çalışmasında da öğretmen adayları, mezun olduktan sonra sertifika şeklindeki formasyon eğitiminin verimli olmadığını belirterek, pedagojik formasyon eğitiminin lisans eğitimine dahil edilmesini ve daha uzun bir sürece yayılmasını gerekli gördüklerini ifade etmişlerdir.

Yazıbaşı $(2018,39)$ 'nın çalışmasında İlahiyat/İslami İlimler, İslam ve Din Bilimleri, Dini İlimler Fakülteleri lisans programları içinde 2017-2018 eğitim-öğretim yılından itibaren seçmeli olarak verilmeye başlanan formasyon derslerine yönelik yapılan çalışmada, öğretmen adaylarının öğretmen olma yeterliği bakımından olumlu algı içinde oldukları üzerinde durulmuştur.

Diğer yandan hizmet öncesinde formasyon derslerini lisans aşamasında almış olmak, sertifika şeklinde dışardan alınan eğitime kıyasla verimli olmakla beraber, lisans döneminde formasyon eğitiminin niteliği ve imkanı bir başka tartışma alanını oluşturmaktadır.

Örneğin aday öğretmenlerin değer eğitimi etkinliklerine yönelik görüşleri üzerinde yapılan bir çalışmada ilginç bir sonuç ortaya çıkmıştır. Hizmet öncesi lisans döneminde değer eğitimi dersini okuyan aday öğretmenlerin, öğretmenlik uygulaması yaparken derslerde öğrencilerin pasif olduğu etkinlikleri daha çok tercih etmeleri istatistiksel olarak anlamlı bulunmuş, lisans döneminde değer eğitimi almayan adaylarla kıyaslandığında bu anlamlı fark dikkat çeken bir bulgu olmuştur (Algur, 2019, 349 - 350). Bu durum yazarın da vurguladığı gibi lisans döneminde bir dersin yer alıp almaması kadar o dersin hangi yaklaşım, yöntem, materyal ve yetkinlik içinde verilip verilmemesinin de dikkate alınmasını önemli hale getirmektedir.

Süreç içinde formasyon eğitimini verimli yapan ya da başarısız kılan temel etkenler nelerdir sorusu anlam kazanmaktadır. Ayrıca Akyıldız, Altun ve Kasım (2020, 123 - 126)'ın çalışmasında da belirtilen, sınıfların belirli bir alan açısından homojen olma niteliği, stajyer olmanın 
A. YEMENICI / Teacher Candidate Training and Training Process from the Perspective of Religious Culture and Moral Knowledge Teacher Candidates and Adviser Teachers I 259 daha çok mesleğe başlamamış bir öğrenci olarak algılanması gibi ana temalar hem bizim çalışmamızda hem de farklı çalışmalarda tartışılan odak noktaları oluşturmaktadır.

Özellikle alan saha ilişkisi ve formasyon eğitimi arasındaki bağlantının lisans eğitiminde nasıl kurulduğu odak noktayı oluşturmaktadır.

Alan saha ilişkisinin teorik temelleri ve dayandığı saha deneyimleri, bir lisans öğrencisinin zihin dünyasında kurulamadığı durumlarda oluşan ayrışma, sınıf ve okul pratiğinde sadece formasyon dersleri ile kapatılamayacak boyutlara ulaşabilmektedir. Hatta bu durumda formasyon dersleri, yerine getirilmesi gereken sadece bir prosedür olarak görülmektedir. Örgün eğitim kurumlarındaki öğrencilerin ve velilerinin ilahiyat alanından beklenti, talep ve ihtiyaçları ile derslerin öğretim içerikleri aday öğretmenin gözünde karşılıksız kalabilmektedir.

Çalışmamızdan elde edilen bulgularda, alan saha ilişkisinin iyi kurulduğu aday öğretmen deneyimlerinde, hem formasyon eğitimi hem de alan bilgisi bakımından sınıf pratiğinde sorun yaşanmadığı görülmektedir.

Alan derslerinin içerikleri, felsefi yaklaşımları, program tasarımları, ihtiyaç analizlerinin yapılış durumları ve öğretim yaklaşım biçimleri, bu bağlamda tartışılması gereken eksenleri oluşturmaktadır. Söz konusu arayıştan hareketle, lisans döneminde din felsefesinin okullarda öğretime yansıması bakımından sunacağı katkının boyutları farklı çalışmalara konu olmaktadır (Altaş - Büyük, 2018, 130).

$\mathrm{Bu}$ anlamda DKAB bölüm mezunlarının alanı isteyerek tercih etmeleri (Özdemir - Kavak, 2012, 549) ve öğretmenlik uygulamasına bu bölümden katılan öğretmen adaylarının alan saha ilişkisi ve formasyon eğitimi açısından hem zihinsel hem de öğretmenlik uygulaması bakımından daha hazır oldukları yönündeki bulgular, çalışmamızla örtüşen veriler sunmaktadır (Çapcıoğlu - Kızılabdullah, 2020, 67).

Araştırma bulgularından hareketle şu sonuçlar üzerinde durulabilir.

- Formasyon eğitiminin verimliliğine yönelik yapılan değerlendirmelerde bazı etkenlerin belirgin olduğu görülmüştür. 
260 | A. YEMENICİ / Din Kültürü ve Ahlak Bilgisi Aday Öğretmenleri ve Danışman Öğretmenlerinin Gözüyle Aday Öğretmen Yetiştirme Eğitimi ve Süreci

1. Formasyon derslerinin yaklaşım, yöntem ve teknik olarak veriliş biçimleri,

2. Formasyon derslerinin alaninda uzman akademisyenlerce verilip verilmediği ve fakültelerin bu anlamda yeterli öğretim elemanlarına sahip olma durumu,

3. Formasyon derslerine ve uygulamalarına ayrilan zamanın yıllar ve dönemler açısından yeterli sürelere yayılması,

4. İlahiyat alan derslerinin alınış süreci ile formasyon dersleri arasında yaşanan disiplinler arası ilişkisel durum ve alan saha ilişkisinin niteliği,

5. Stajyerlikte formasyon eğitiminin, öğrenci gözünde bir öğretmenlik meslek eğitimi değil, geçilmesi gereken bir ders olarak algilanmasından doğan motivasyon durumu,

6. Formasyon derslerinde sinıfların belirli bir alan açısından homojen/heterojen olma (sınıf, matematik DKAB öğretmenliği) niteliği.

- Lisans içinde verilen formasyon eğitimi, sertifika formasyon eğitimine kıyasla daha verimli ve başarılı olarak deneyimlenmiştir.

- Stajyer öğretmen adaylarının öğrenci olmaları nedeniyle yaşadıkları motivasyon düşüklüğü, ancak göreve başladıktan sonra doğrudan sınıfa girmeden danışman öğretmen rehberliğindeki adaylık sürecinde okul - sinıf pratiği ve öğretmenlik uygulaması ile giderilebilmiştir.

- İlahiyat alan dersleri ile sahanın ihtiyaç ve talepleri arasındaki ilişkinin teorik ve pratik temelleri iyi kurulamadığında, hem alan dersleri hem de formasyon dersleri açısından, aday öğretmenlik döneminden başlamak üzere mesleki gelişimin ilerleyen aşamalarında yetersizlik algısı ortaya çıkmaktadır.

Bu sonuçlardan hareketle şu öneriler üzerinde durulabilir.

- Okul deneyimi ve öğretmenlik uygulaması bakımından, lisansta formasyon eğitiminde öğrenci olma nedeniyle yaşanan motivasyon düşüklügünü gidermek amacıyla, atandıktan sonra adaylık eğitimi öğrencilikten mesleğe başlama bakımından gerekli olan hazırlayıcı bir aşama olarak ele alınabilir. Bu iki aşama birbirinin alternatifi olarak değil, birbirinin tamamlayıcısı olarak görülebilir.

- Aday öğretmenler, doğrudan öğrenci ile karşı karşıya bırakılmadan ve deneme yanılma sürecine maruz kalmadan okula, sınıfa 
A. YEMENICI / Teacher Candidate Training and Training Process from the Perspective of Religious Culture and Moral Knowledge Teacher Candidates and Adviser Teachers | 261 ve öğrenciye kısaca mesleğe yeterince 1sındıktan sonra tek başlarına derslere ve nöbetlere devam edebilirler.

- İlahiyat alan dersleri ile sahanın ihtiyaç ve talepleri arasındaki ilişkinin teorik ve pratik temellerini saptayan çok yönlü ihtiyaç analizleri yapilabilir.

\section{Kaynakça}

Akyıldız, Salih vd.. "Adaylık Eğitimi Uygulama Sürecinin Aday Öğretmenlerin Görüşlerine Göre İncelenmesi". IBAD Sosyal Bilimler Dergisi 6 (2020), 117-131. DOI: 10.21733/ibad.655108

Akyüz, Yahya. "Öğretmen Yetiştirme Tarihimizde Nitelik Arayışına İki

Örnek". Eğitimde Nitelik Geliştirme: Eğitimde Arayışlar I. Sempozyumu Bildiri Metinleri. ed. İlhami Fındıkçı. 222-227. İstanbul: Kültür Koleji Yayınları, 1991.

Akyüz, Yahya. Türkiye'de Öğretmenlerin Toplumsal Değişmedeki Etkileri (1839 - 1950). Ankara: Pegem Akademi Yayınları, 2. Basım, 2012.

Alataş, Hürriyet. Türkiye'de 2016 Yılında Uygulanan "Aday Öğretmen Yetiştirme Programı" Uygulamasının Değerlendirilmesi. Van: Yüzüncü Yil Üniversitesi, Sosyal Bilimler Enstitüsü, Yüksek Lisans Tezi, 2017.

Algur, Hüseyin. “Adaylık Eğitimi Alan Öğretmenlerin Değer Öğretimi Etkinlikleri Hakkındaki Görüşleri”. Amasya İlahiyat Dergisi - Amasya Theology Journal 12 (Haziran 2019), 319-356. https://doi.org/10.18498/amailad.579981

Altaş, Nurullah - Büyük, Celal. "Öğretmen Yetiştiren Bir Kurum Olarak

İlahiyat Eğitiminin Genel Hedefleri Altında Din Eğitimi ve Din Felsefesi Eğitimi İlişkisi (Din Eğitimi ve Din Felsefesi İlişkisi Özel Amaçlara Nasıl Yansımalı?)". Din ve Felsefe Araştırmaları 1/2 (Aralık 2018), 115-133.

https://dergipark.org.tr/tr/pub/udfad/issue/42095/506389

Atay, Demir Yalaz. Öğretmen Ĕ̆itiminin Değişen Yüzü. Ankara: Nobel Yayınları, 2003.

Aydın, Muhammet Şevki. Cumhuriyet Döneminde Din Eğitimi Öğretmeni Yetiştirme ve İstihdamı. İstanbul: Dem Yayınları, 2016. 
262 | A. YEMENICİ / Din Kültürü ve Ahlak Bilgisi Aday Öğretmenleri ve Danışman Öğretmenlerinin Gözüyle Aday Öğretmen Yetiştirme Eğitimi ve Süreci

Aydın, Muhammet Şevki. Din Ĕ̆itimi Bilimi. Kayseri: Kimlik Yayınları, 2017.

Balkar, Betül - Şahin, Sevilay. “Aday Öğretmenlere Yönelik Mentörlük Programının Uygulanmasına İlişkin Eğitimcilerin Görüşleri”. The Journal of Academic Social Science Studies 29 (2014), 83-100. doi number: http://dx.doi.org/10.9761/JASSS2547

Balkar, Betül - Şahin, Sevilay. "Yeni Bir Öğretmen Yetiştirme Yaklaşımı Olarak Göreve Başlatma Programı". Mersin Üniversitesi Ĕ̆gitim Fakültesi Dergisi 11/1 (2015), 1-19. https://dergipark.org.tr/tr/download/article-file/161068

Binbaşıŏlu, Cavit. Öğretmen Yetiştirme Açısından Türkiye'de Ĕ̆itim Bilimleri Tarihi. İstanbul: MEB. Yayınları, 1995.

Cengiz, Ekrem. “Türkiye'de İlk Kez Uygulanan Aday Öğretmen Yetiştirme Sürecine İlişkin Öğretmen Görüşleri". Yüzüncü Y $Y_{l l}$ Üniversitesi Eğitim Fakültesi Dergisi 15/1 (2018), 932-968. http://dx.doi.org/10.23891/efdyyu.2018.92

Creswell, John W. Nitel Araştırma Yöntemleri: Beş yaklaşıma Göre Nitel Araştırma ve Araştırma Deseni. çev. Mesut Bütün - Selçuk Beşir Demir vd.. Ankara: Siyasal Kitapevi, 3. Basım, 2016.

Çapcioğlu, Fatma - Kızılabdullah, Yıldız. “Uygulama Öğretmeni ve Ögrencilerinin Ankara Üniversitesi İlahiyat Fakültesi Öğretmenlik Uygulaması Sürecine Yönelik Görüşleri”. Dini Araştırmalar Dergisi Prof. Dr. Beyza Bilgin Özel Sayısı 23 (58) (2020), 51-78. https://doi.org/10.15745/da.797997

Çetin, Şaban. "Öğretmenlik Mesleğinde Değerler". Öğretmen Yetiştirme Sistemimiz. ed. Mustafa Ergün vd.. 165-191. Ankara: Pegem Akademi Yayınları, 2018.

Çınar, Fatih. "Din Öğretiminde Öğretmen Yetiştirme Sorunu". Uluslararası Sosyal Araştırmalar Dergisi 9/46 (2016), 493-513. https://www.sosyalarastirmalar.com/cilt9/sayi46_pdf/5egitim/cina r_fatih.pdf

Darlink - Hammond, Linda. "İyi Öğretmenlerin Mesleği Bırakmasını Engellemek Neden Önemlidir, Liderler Neler Yapabilir". çev. Esra Çakar Özkan vd.. Eğitim Programlarında Güncel Sorunlar. Ornstein C. Allan vd.. 111-119. Ankara: Pegem Akademi Yayınları, 2016. 
A. YEMENICI / Teacher Candidate Training and Training Process from the Perspective of Religious Culture and Moral Knowledge Teacher Candidates and Adviser Teachers | 263

Doğan, Recai - Altaş, Nurullah. "İlköğretim Din Kültürü ve Ahlak Bilgisi Öğretmenlerinin Yeterlik Ölçeği Üzerine Bir Ön Araştırma”. Ankara Üniversitesi İlahiyat Fakültesi Dergisi 43/1 (2002), 109-122.

Ev, Halit. "Din Kültürü ve Ahlak Bilgisi Dersi Öğretmenlerinin Yeterlikleri Bağlamında İlahiyat Fakülteleri ve Öğretmen Yetiştirme Sistemini Yeniden Yapılandırma". Manisa Celal Bayar Üniversitesi Sosyal Bilimler Dergisi 13/4 (Aralık 2015), 83-100. https://doi.org/10.18026/cbusos.41399

Gökçe Toker, Asiye. "Sınıf Öğretmenlerinin Adaylık Dönemlerinde Yaşadıkları Mesleki Sorunlar". Dicle Üniversitesi Ziya Gökalp Eğitim Fakültesi Dergisi $21 \quad$ (2013), 137-156. https://dergipark.org.tr/tr/download/article-file/786874

Gökyer, Necmi. "Öğretmen Adaylarının Hizmet Öncesi Eğitimleri Sürecinde Derslerin İşlenişine İlişkin Görüşleri". Milli Eğitim 196, (2012), 124-141. Erişim 24 Haziran 2020. https://dergipark.org.tr/tr/download/article-file/442222

Gültekin, Mehmet. “Dünyada Öğretmen Yetiştirme”. Öğretmen Yetiştirme Sistemimiz: Dün, Bugün ve Yarın. ed. Mustafa Ergün vd. 403-440. Ankara: Pegem Akademi Yayınları, 2018.

Gün, Ayşegül. "Pedagojik Formasyon Eğitimi Alan İlahiyat Fakültesi Öğrencilerinin Mesleki Yeterlik Algıları ve Pedagojik Formasyon Programına İlişkin Görüşleri: Amasya Üniversitesi Örneği". Amasya Üniversitesi İlahiyat Fakültesi Dergisi / 8 (Haziran 2017), 125-171. https://doi.org/10.18498/amauifd.325833

Güneş, Firdevs. "Öğretmen Yetiştirme Yaklaşım ve Modelleri”. Ahi Evran Üniversitesi Kırşehir Ĕ̆itim Fakültesi Dergisi, 17/3 (Aralık 2016), 413435.

http://kefad2.ahievran.edu.tr/archieve/pdfler/Cilt17Sayi3/JKEF_17 _3_2016_413-435.pdf

Hurn, Christopher J. Eğitim Sosyolojisi: Okulun İmkân ve Sinırları. çev. Mustafa Sever vd.. Ankara: Pegem Akademi Yayınları, 2018.

Ingersoll, Richard. "Yeni Başlayan Öğretmenlerin Adaylık Eğitimi: Veriler Bize ne Anlatıyor?". çev. Öner Uslu vd.. Eğitim Programlarmda Güncel Sorunlar. Ornstein C. Allan vd.. 261-268. Ankara: Pegem Akademi Yayınları, 2016. 
264 I A. YEMENICİ / Din Kültürü ve Ahlak Bilgisi Aday Öğretmenleri ve Danışman Öğretmenlerinin Gözüyle Aday Öğretmen Yetiştirme Eğitimi ve Süreci

Işıkdoğan, Davut. “Din Kültürü ve Ahlak Bilgisi Dersi Öğretmenlerinin Yeterlikleri". Türkiye'de Okullarda Din Öğretimi. ed. Recep Kaymakcan vd.. 553-569. İstanbul: Değerler Eğitimi Merkezi Yayınları, 2011.

İlyas, İbrahim Emre vd.. Türkiye'de Aday Öğretmen Yetiştirme Modeli İzleme ve Değerlendirme. Siyaset Ekonomi ve Toplumsal Araştırma Vakfı SETA, 2016. Erişim 2019. https://setav.org/assets/uploads/2017/04/AdayOgretmenler.pdf

Karadağ, Engin - Dulay, Sabiha. Öğretmen Tipolojileri: Öğretmenler Sinıfta Nasıl Davranır. Ankara: Pegem Akademi yayınları, 2017.

Kılıç, Burcu - Özbey, Nüket. "Tek Başına Yaşayarak Öğretmenliği Öğrenme: 'Yapılandırmacı Stajyerlik'". Ö̈̆retmenlik Halleri: Türkiye'de Öğretmen Olmak Üzerine Nitel Bir Araştırma. ed. Mustafa Sever - Ahmet Aypay. 1-47. Ankara: Pegem Akademi Yayınları, 2. Basım, 2016.

Koç, Ahmet. "Din Kültürü ve Ahlak Bilgisi Öğretmenlerinin Öğretme Öğrenme Sürecine İlişkin Yeterlikleri". Türkiye'de Okullarda Din Öğretimi. ed. Recep Kaymakcan vd.. 523-552. İstanbul: Değerler Eğitimi Merkezi Yayınları, 2011.

Kozikoğlu, İshak - Senemoğlu, Nuray. "Mesleğe Yeni Başlayan Öğretmenlerin Karşılaştıkları Güçlükler: Nitel Bir Çözümleme". Eğitimde Nitel Araştırmalar Dergisi, - Journal of Qualitative Research in Education, 6/3 (2018), 341-371. Erişim 2019 https://dergipark.org.tr/tr/pub/enad/issue/40655/490127

Kozikoğlu, İshak - Soyalp, Hayriye. “Aday Öğretmenlerin, Danışman

Öğretmenlerin ve Okul Yöneticilerinin Aday Öğretmen Yetiştirme Programına Yönelik Görüşlerinin İncelenmesi". Hacettepe Üniversitesi Eğitim Fakültesi Dergisi, 33/4 (2018), 934-952. https://dergipark.org.tr/tr/download/article-file/557828

K. Wong, Harry vd.. “Dünya Yeni Adaylık Eğitimiyle İlgili Bize Neler Öğretebilir?". çev. Öner Uslu vd.. Eğitim Programlarında Güncel Sorunlar. Ornstein C. Allan vd.. 242-249. Ankara: Pegem Akademi Yayınlar1, 2016.

Mayring, Philip. Nitel Sosyal Araştırmaya Giriş. çev. Adnan Gümüş vd.. Ankara: BilgeSu, 2001. 
A. YEMENICI / Teacher Candidate Training and Training Process from the Perspective of Religious Culture and Moral Knowledge Teacher Candidates and Adviser Teachers I 265

MEBTTKBÖAK, Milli Eğitim Bakanlığı Talim ve Terbiye Kurulu Başkanlığının 29 Haziran 2020 tarih ve 12 sayılı Öğretmenlik Alanları Kararı. Türkiye: Milli Ĕ̆itim Bakanlığı Tebliğler Dergisi 2754 (Temmuz 2020). Erişim $11 \quad$ Ekim 2020. file:///C:/Users/YBU/Downloads/2754_Temmuz_2020.pdf

MEBAÖYP, Milli Eğitim Bakanlığı Aday Öğretmen Yetiştirme Programı Konulu Valiliklere Gönderilen Bakanlık Yazısı/ 17 Ekim 2016, İlgi d. Erişim Temmuz 2020. https://kirikkale.meb.gov.tr/meb_iys_dosyalar/2016_10/18125853_a day_ogretmen_yetistirme_programi.pdf

MEBAÖYS, Milli Eğitim Bakanlığı Aday Öğretmen Yetiştirme Sürecinin Ayrıntıları Belli Oldu/ 18 Şubat 2016. Erişim 20 Şubat 2016. http://www.meb.gov.tr/aday-ogretmen-yetistirme-surecininayrintilari-belli-oldu/haber/10465/tr

MEBAÖYSIYY. Aday Öğretmen Yetiştirme Sürecine İlişkin Yönerge. Türkiye: Milli Eğitim Bakanlığı Tebliğler Dergisi 2702 (Mart 2016). Erişim 28 Haziran 2020. http://mevzuat.meb.gov.tr/dosyalar/1769.pdf

Merriam, Sharan B. Nitel Araştırma Desen ve Uygulama İçin Bir Rehber. çev. Selahattin Turan vd.. Ankara: Nobel Akademik Yayıncilık, 2013. ÖAYDY, Öğretmen Atama ve Yer Değiştirme Yönetmeliği, Resmi Gazete 29329 (17 Nisan 2015). Erişim 14 Eylül 2019. https://www.resmigazete.gov.tr/eskiler/2015/04/20150417-4.htm

ÖSB, Öğretmen Strateji Belgesi 2017 - 2023. Resmi Gazete 30091 (9 Haziran 2017). Erişim 24 Haziran 2020.

https://www.resmigazete.gov.tr/eskiler/2017/06/20170609-13.htm

Özdemir, Şuayip - Kavak, Rahime. “İlköğretim Din Kültürü ve Ahlak Bilgisi Eğitimi Bölümü Öğrencilerinin Eğitim-Öğretim Beklentileri ve Sorunları (Atatürk ve Erciyes Üniversiteleri Örneği)". The Journal of Academic Social Science Studies 5/7, (2012), 529-551.

Özan, Mukadder Boydak - Nanto, Zülküf. “Okul Yöneticilerinin Aday Öğretmenlik Süreci ile İlgili Görüşleri”. Kırıkkale Üniversitesi Sosyal Bilimler Dergisi (KÜSBD) 8/1 (Ocak 2018), 187-202. https://dergipark.org.tr/tr/download/article-file/434439 
266 | A. YEMENICİ / Din Kültürü ve Ahlak Bilgisi Aday Öğretmenleri ve Danışman Öğretmenlerinin Gözüyle Aday Öğretmen Yetiştirme Eğitimi ve Süreci

Özoğlu, Murat vd.. Türkiye ve Dünyada Öğretmenlik: Retorik ve Pratik. Ankara: Eğitim Birsen Yayınları, 2013.

Öztürk, Cemil. Atatürk Devri Öğretmen Yetiştirme Politikası. Ankara: Türk Tarih Kurumu, 1996.

Palmer, Parker J. “Öğretmenin Kalbi”. çev. Esra Çakar Özkan vd.. Eğitim Programlarında Güncel Sorunlar. Ornstein C. Allan vd.. 55-67. Ankara: Pegem Akademi Yayınları, 2016.

Patton, Michael Quinn. Nitel Araştırma ve Değerlendirme Yöntemleri. çev. Mesut Bütün - Selçuk Beşir Demir (ed.). Pegem Akademi Yayınları. Ankara: 2014.

Saldana, Johnny. Nitel Araştırmacılar İçin Kodlama El Kitabı. çev. Aysel Tüfekçi Akcan - Süleyman Nihat Şad (ed.). Pegem Akademi Yayınları. Ankara: 2019

Sarıkaya, İsmail vd.. “Aday Öğretmen Yetiştirme Sürecinin Aday ve Danışman Sınıf Öğretmenlerinin Görüşleri Kapsamında Değerlendirilmesi: Bir Karma Yöntem Çalışması". Gazi Eğitim Fakültesi Dergisi [GEFAD / GUJGEF] 37/3 (Aralık 2017), 939-989. http://www.gefad.gazi.edu.tr/tr/download/article-file/393029

Seferoğlu, Süleyman S. "Öğretmen Yeterlikleri ve Mesleki Gelişim”. Bilim ve Aklın Aydınlığında Ĕ̆itim. 58 (2004), 40-45. Erişim 24 Haziran 2018.

http://yunus.hacettepe.edu.tr/ \%20sadi/yayin/Seferoglu_Ogretme n_Yeterlikleri_BAAE_2004-58.pdf

Topsakal, Cem - Duysak, Ahmet. “Aday Öğretmen Yetiştirme Sürecine İlişkin Aday Öğretmenler ve Diğer Paydaşların Görüşleri". Sakarya University Journal of Education 7/3 (Aralık 2017), 625-638. https://doi.org/10.19126/suje.368228

Yazıbaşı, Muhammet Ali. “İlahiyat/İslami İlimler Fakültesinde Pedagojık Formasyon Derslerini Tercih Eden Öğrencilerin Derslerle İlgili Değerlendirmeleri". İlahiyat Alanında Akademik Çalışmalar. ed. Ramazan Biçer. 19-40. Ankara: Gece Kitaplığı Yayınları, 2018.

Yıldırım, Ali - Şimşek, Hasan. Sosyal Bilimlerde Nitel Araştırma Yöntemleri. Ankara: Seçkin Yayıncilık, 9. Basım, 2013.

Zengin, Zeki S. Tanzimat Dönemi Osmanlı Örgün Ĕ̆itim Kurumlarında Din Eğitimi ve Öğretimi (1839-1876). İstanbul: MEB Yayınları, 2004. 